Canadian

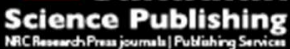

Environmental Reviews Dossiers environnement

\title{
Antimicrobial nanomaterials against biofilms: an alternative strategy
}

\begin{tabular}{|c|c|}
\hline Journal: & Environmental Reviews \\
\hline Manuscript ID & er-2016-0046.R3 \\
\hline Manuscript Type: & Review \\
\hline Date Submitted by the Author: & $18-$ Oct-2016 \\
\hline Complete List of Authors: & $\begin{array}{l}\text { Liu, Chunhua; Shenzhen Institutes of Advanced Technology } \\
\text { Guo, Jing; Xinjiang Institute of Ecology and Geography } \\
\text { Yan, Xiaoqing; Shenzhen Institutes of Advanced Technology } \\
\text { Tang, Yongbing; Shenzhen Institutes of Advanced Technology } \\
\text { Mazumder, Asit; University of Victoria, Biology } \\
\text { Wu, Shikai; Guangzhou Institute of Advanced Technology } \\
\text { Liang, Yan; Shenzhen Institutes of Advanced Technology, SIAT, Shenzhen } \\
\text { Institutes of Advanced Technology, CAS }\end{array}$ \\
\hline Keyword: & biofilm, biostatic nanoparticle-based coatings, antimicrobial, disinfection \\
\hline
\end{tabular}


1 ARTICLE TYPE: Review article

2 TITLE: Antimicrobial nanomaterials against biofilms: an alternative

3

4 AUTHORS: Chunhua Liü, Jing Guo ${ }^{\#}$, Xiaoqing Yan, Yongbing Tang, Asit

5

7

9

10

11

12
Mazumder*, Shikai Wu, Yan Liang**

INSTITUTION: $\quad$ Shenzhen Institutes of Advanced Technology, Chinese

Academy of Sciences

ADDRESSES: $\quad 1068$ Xueyuan Blv, University Town, Xili, Shenzhen 518055,

P.R. China

CORRESPONDING AUTHOR*: Prof. Yan Liang, Ph. D, Phone: +86-755-86585239;

fax: +86-755-86585222; email: yan.liang@siat.ac.cn 
13 Antimicrobial nanomaterials against biofilms: an alternative

14

\section{strategy}

Chunhua Liu ${ }^{1,2 \#}$, Jing Guo ${ }^{2 \#}$, Xiaoqing Yan ${ }^{2}$, Yongbing Tang ${ }^{2}$, Asit Mazumder $^{2,3 *}$, Shikai $\mathrm{Wu}^{4}$, Yan Liang ${ }^{1,2 * *}$

${ }^{1}$ Xinjiang Institute of Ecology and Geography, Chinese Academy of Sciences, Urumqi, 830011, P. R. China

${ }^{2}$ Shenzhen Institutes of Advanced Technology, Chinese Academy of Science, Shenzhen, 518055, P. R. China

${ }^{3}$ Department of Biology, University of Victoria, Victoria, BC, V8N 6A7, Canada

${ }^{4}$ Guangdong Key Laboratory of Membrane Materials and Membrane Separation, Guangzhou Institute of Advanced Technology, Chinese Academy of Science, Guangzhou, 511458, P. R. China

First authors ${ }^{\#}$ : Chunhua Liu and Jing Guo contribute equally to this work.

Corresponding authors ${ }^{*}{ }^{* *}:$ Tel: +86 755-86585247, e-mail: yan.liang@siat.ac.cn (Yan Liang); mazumder@uvic.ca (Asit Mazumder) 


\section{Abstract}

Microbial adhesion to surfaces and the consequent biofilm formation under various environmental conditions is a common ecological phenomenon. Although biofilms play crucial beneficial roles in many processes, they can also cause serious problems for food, biomedical, environmental and industrial sectors, leading to higher costs of production and equipment maintenance, and negative public health and environmental impacts. Biofilms are difficult to eradicate due to their resistance to conventional antimicrobial applications. Consequently, attention has been devoted to new emerging nanomaterials (NMs) for their remarkable antimicrobial function. Understanding the inactivation mechanisms is the key to increase the efficiency of nanoparticles (NPs) and enhance the feasibility of their application against various microorganisms under different environments. In this paper, we review the activities of NPs as antimicrobial agents. We also discuss the mechanisms and factors contributing to antimicrobial properties of NPs. In addition, we describe some of the approaches employing NPs as effective antimicrobial agent, and associated challenges and problems in developing NPs as effective antibiofilm agents.

Key words: biofilm, biostatic nanoparticle-based coatings, antimicrobial, disinfection

\section{Introduction}

Adhesion of microbes to surfaces and the subsequent biofilms have been very common in diverse environments. Biofilms are community structures of microbes surrounded by a hydrated matrix composed of extracellular polymeric substances 
52 (EPS), which is secreted by these indwelling microbes and mainly contain 53 polysaccharides, proteins, lipids and nucleic acids, to protect or facilitate their growth 54 in hostile environments (Flemming and Wingender 2010). Although important 55 engineering implication in wastewater industries (Nicolella et al. 2000; Srivastava and 56 Majumder 2008) and petroleum pollution elimination (Dos Santos et al. 2008), 57 biofilms are problematic in infectious diseases (Hall-Stoodley et al. 2004), food 58 (Simões et al. 2010), environmental (Inbakandan et al. 2013; Ren et al. 2014) and 59 biomedical fields (Sihorkar V et al. 2001) because they are mostly detrimental to 60 health, social manufacture and living activities (Davey and O'toole 2000; Beyth et al.

2015). Several researchers suggested that the importance of biofilm control is severely underrated (Simões et al. 2010; Pelgrift and Friedman 2013).

Under different environmental conditions, microbes colonize and develop biofilms on diverse surfaces including those of natural aquatic systems, water pipes, living tissues, tooth and medical devices (Donlan 2002; Markowska et al. 2013). Most microorganisms on earth live in various aggregates biofilm, such as bacteria, fungi, archaea, and viruses (Donlan 2002; Skraber et al. 2005; Wingender and Flemming 2011). Biofilm formation comprises a sequence of steps: formation of a conditioning film; transport of the microorganisms from the bulk liquid to adhesion surface; initial adhesion of microorganisms to the surface; biofilm growth; and biofilm maturation (equilibrium between the accumulation and detachment) (Fig.1) (Ferreira et al. 2010; Simões et al. 2010). Because of the complex matrix structure, biofilms are more tolerant to antimicrobials than planktonic cells (Khan and Khan 2016), and frequently 
develop antibiotic resistance, thus being more difficult to control. As a result, conventional approaches (e.g. mechanical cleaning, ultraviolet radiation, traditional chemical antimicrobials) were utilized to counter biofilms. And some novel approaches have been studied as potential strategies for biofilms control (Flemming and Ridgway 2008; Simões et al. 2010; Chen et al. 2013), such as quorum sensing inhibitors (QSIs) (Rasmussen and Givskov 2006), antimicrobial peptides (Park et al. 2011b), enzymes (Thallinger at al. 2013), nanomaterials (NMs) (Bakkiyaraj and Pandian 2014; Qayyum and Khan 2016), biomimetic surfaces (Salta et al. 2010; Sun and Qing 2011). However, many of these approaches have demonstrated a modest antimicrobial efficacy and still have limitations in successfully controlling biofilms.

Among the above methods to biofilms control, nanotechnology is highly promising and has received an enormous amount of attention for effective antimicrobial ability (Li et al. 2008b; Bakkiyaraj and Pandian 2014; de Souza et al. 2014; Qayyum and Khan 2016). Nanoparticles (NPs) are particles possessing grain sizes on the order of 1-100 $\mathrm{nm}$ (Buzea at al. 2007). NMs are highly reactive and preferred over other antimicrobial agents mainly because of their surface area is exceedingly large relative to their size. NMs possess antimicrobial and antibiofilm properties against various bacterial, fungal and other microorganism species (Li et al. 2008b; Huh and Kwon 2011; Bakkiyaraj and Pandian 2014; Hossain et al. 2014; Beyth et al. 2015; Qayyum and Khan 2016). Consequently, NMs could serve as an alternative to inactivate microorganisms. Unlike the conventional chemical antimicrobials, these antimicrobial NMs are cost-effective, easy-to-use, relatively 
inert in water and are not strong oxidizers.

In this review the potentials of various NMs as antimicrobials for the biofilms control are described. The antimicrobial mechanisms of action and major applications of NPs are provided. The barriers for their full-scale application and the research needs for overcoming these barriers are also discussed. We also look at the potential impact of NMs on human and ecosystem health as well as any potential interference with treatment processes and provide directions for future research.

\section{Antimicrobial and antibiofilm properties and application of NMs}

The antimicrobial NMs discussed in this paper fall into three general categories: metals and metal oxides nanoparticles, naturally occurring antimicrobial substances, and carbon-based NMs. High surface area to volume ratios and unique physicochemical properties of various NMs are believed to contribute to effective antimicrobial activities. The major antimicrobial mechanisms reported in the literature are summarized in Fig. 2. These NPs interact with microbial cells through a variety of mechanisms including: 1) photocatalytic production of reactive oxygen species (ROS) that damage cellular and viral components, 2) compromising the bacterial cell wall/membrane, 3) interrupting transmembrane electron transfer, and 4) inhibition of enzyme activity and DNA synthesis (Maness et al. 1999; Rabea et al. 2003; Pal et al. 2007; Li et al. 2008b). The antimicrobial and antibiofilm activity of different types of NMs against different microbes are listed in Table 1 and Table 2. Moreover, Table 3 summarizes NMs with their antimicrobial mechanisms, as well as their current and potential uses. For future industrial scale application of NPs as effective antimicrobial 
118

119

120

121

122

agents, we need a better understanding of the mechanisms of how NMs influence antimicrobial activity.

\subsection{Silver nanoparticles (Ag NPs)}

Nanoparticles of metal and metal oxides have been widely studied for their antimicrobial activities, such as silver $(\mathrm{Ag})$, iron oxide $\left(\mathrm{Fe}_{3} \mathrm{O}_{4}\right)$, titanium oxide $\left(\mathrm{TiO}_{2}\right)$, and zinc oxide $(\mathrm{ZnO})$. Among them, silver nanoparticles are renowned for their influential antimicrobial activity, and have been the most widely used metal nanoparticles as an effective antimicrobial agent in various fields like medical, textile, and building industries. Silver has been used since ancient times for treating wide range of illnesses (Rai et al. 2009).

As previously stated, silver ions interact with sulfur-containing and phosphorus-containing groups of proteins of the cell wall and plasma membrane of bacteria, rendering them inactive and causing aggregation of these proteins (Hindi et al. 2009; Lara et al. 2009; Blecher et al. 2011; Knetsch and Koole 2011). Binding of silver ions to negatively charged parts of the membrane leads to perforation of the membrane, leakage of the cellular compounds, and cell death (Knetsch and Koole 2011). Some silver ions pass through the membrane into the cytoplasm of the bacterial cell, causing damage to protein and nucleic acid inside bacteria (Lara et al. 2010; Blecher et al. 2011). Once inside the cell, silver NPs target and damage bacterial DNA and respiratory enzymes, leading to loss of the cell's replicating abilities and ultimately cell death (Hindi et al. 2009; Rai et al. 2009). In addition, silver NPs attack the respiratory chain and cell division that finally lead to cell death, 
while concomitantly releasing silver ions that enhance bactericidal activity (Blecher et al. 2011; Huh and Kwon 2011). The generation of ROS on silver NPs was also demonstrated (Hindi et al. 2009; Gordon et al. 2010; Lara et al. 2010).

Silver NPs show stronger antimicrobial activity than metallic silver, which is mostly dependent upon the size, shape, and released silver ions $\left(\mathrm{Ag}^{+}\right)$of the nanoparticles (Knetsch and Koole 2011; Pelgrift and Friedman 2013). Ag NPs with smaller size and larger surface area achieve increased ability to pass through cell walls and membranes into the cytoplasm (Gordon et al. 2010; Blecher et al. 2011; Knetsch and Koole 2011; Pelgrift and Friedman 2013). In a study by Pal et al. (2007), triangular or truncated particles were found to be more effective in bacterial killing activity than rods and spherical particles. In addition, there may be the formation of a silver oxide layer on the nanoparticle surface and leading to the formation of $\mathrm{Ag}^{+}$ reservoir (Knetsch and Koole 2011). Xiu et al. (2012) demonstrated that Ag NPs morphological properties are indirect effectors that primarily influence $\mathrm{Ag}^{+}$release. Therefore the antibacterial activity of Ag NPs could be controlled by modulating $\mathrm{Ag}^{+}$ release, possibly through manipulation of oxygen availability, particle size, shape, and/or type of coating.

Ag NPs have been shown to be effective against a variety of pathogens, including viruses (Rai et al. 2009), fungi (Candida albicans) (Ghosh et al. 2010), and many bacterial species, such as Escherichia coli, Staphylococcus aureus, Bacillus subtilis, and Salmonella typhi (Pal et al. 2007; Shrivastava et al. 2007; Ghosh et al. 2010; Martinez-Gutierrez et al. 2010; Blecher et al. 2011). Moreover, Ag NPs are also 
162

163

164

165

166

167

168

169

170

171

172

173

effective bactericidal agents regardless of the drug-resistance mechanisms against multidrug-resistant Pseudomonas aeruginosa, ampicillin-resistant Escherichia coli O157:H7, and erythromycin-resistant Streptococcus pyogenes (Lara et al. 2010). In a recent study, Leid et al. (2012) showed that silver carbene complexes (SCC) encapsulated in NPs were active against highly resistant bacterial strains, such as methicillin-resistant Staphylococcus aureus (MRSA) and multidrug resistant Acinetobacter baumannii (MRAB), and were active against the biodefence pathogens like Bacillus anthracis and Yersinia pestis. In addition, Ag NPs have also been found to augment the efficacy of other antimicrobial agents, such as penicillin G, amoxicillin, erythromycin, and vancomycin (Shahverdi et al. 2007; Rai et al. 2009). Microbes are also less likely to develop resistance against silver and Ag NPs, as their broad range of targets would require multiple and simultaneous compensatory mutations. As a result, silver can be used to arrest bacterial resistance to antibiotics and enhance their efficacy (Knetsch and Koole 2011; Pelgrift and Friedman 2013).

Ag NPs have also been taken as an alternative strategy for microbial biofilms control (Markowska et al. 2013). Several studies have also shown an important activity of Ag NPs against microbial biofilms, but the precise mechanism underlying their actions remains unresolved. Ag NPs have shown a broad spectrum of antibiofilm activity against bacteria and fungi in disease infection and medicine fields. Roe and his colleagues found catheters coated with bioactive Ag NPs to have significant in vitro antimicrobial activity and prevented biofilm formation of Escherichia coli, Enterococcus, Staphylococcus aureus, coagulase-negative staphylococci, 
184

185

186

187

188

189

190

191

192

193

194

195

196

197

198

199

200

201

202

203

204

205

Pseudomonas aeruginosa and Candida albicans (Roe et al. 2008). Ag NPs surface-modification exhibited strong antibiofilm activity against Staphylococcus epidermidis RP62A (Taglietti et al. 2014). Nano-silver $(25.2 \pm 4 \mathrm{~nm})$ was found to effectively prevent the formation of Pseudomonas aeruginosa biofilms and kill bacteria in established biofilm structures (4-log reduction in the number of colony-forming units) (Martinez-Gutierrez et al. 2013). Habash et al. (2014) noted that $10-\mathrm{nm}$ Ag NPs were most effective than other sizes $(20,40,60$, and $100 \mathrm{~nm})$ in inhibiting the recovery of Pseudomonas aeruginosa biofilm cultures and showed synergy of inhibition when combined with sub-MIC levels of aztreonam. Ag NPs (9.5 $\pm 1.1 \mathrm{~nm}$ ) could effectively inhibit the growth of a planktonic Streptococcus mutans clinical isolate and kill established its biofilms, suggesting that Ag NPs can be used to prevent and treat dental caries (Pérez-Díaz et al. 2015). Compared to control, weaker adherence and disintegrated biofilm formation of Vibrio parahaemolyticus Dav1 treated with a probiotic Bacillus licheniformis cell free extract (BLCFE) coated Ag NPs were observed (Shanthi et al. 2016). Shahrokh and Emtiazi (2013) found that, compared with industrial biocide E-265, low concentration of colloidal nanostructured silver $(40 \pm 10 \mathrm{~nm})(1-2 \mathrm{ppm})$ showed unique antibacterial and antibiofilm activities against pathogenic strains. Silver nanowires did not show an antibacterial activity against test organisms, but showed a promising property of a quorum sensing-mediated inhibition of biofilm in Pseudomonas aeruginosa NCIM 2948 and violacein synthesis in Chromobacterium violaceum ATCC 12472 (Wagh et al. 2013).

Ag NPs also have important anti-biofouling activity in water treatment and 
maritime industries. Recently, one study revealed the anti-microfouling potential of Ag NPs against sixteen different marine biofilm forming bacterial strains (Inbakandan et al. 2013). Another study investigated the effect of Ag NPs on natural bacterial communities, and results showed the increasing concentrations $(0-2000 \mu \mathrm{g} / \mathrm{L})$ of Ag NPs caused a significant decrease in marine biofilm volume and biomass, affecting the relative abundance of major bacterial groups in the biofilm community (Fabrega et al. 2011). EPS and microbial community interactions in the wastewater biofilms play important roles in controlling the antimicrobial effects of Ag NPs, the microbial susceptibility to Ag NPs is different for each microorganism (Sheng and Liu 2011). Fouling-resistant behavior of silver nanoparticle-modified surfaces against the bioadhesion of microalgae has also been detected as EPS also can be produced by microalgae. The Ag NPs coatings revealed a significant surface inhibitory effect against the adhesion of the marine microalga Dunaliella tertiolecta and the freshwater green alga by above $85 \%$ in both seawater and freshwater environments, and contact killing was the predominant antifouling mechanism of Ag NPs-modified surfaces (Ren et al. 2014).

Candida albicans is the most common pathogenic fungus isolated in clinical practice. It has the ability to form biofilms and morphogenetic conversions between yeast and hyphal morphologies contribute to biofilm development and represent an essential virulence factor. Several researches have noted the antibiofilm activity of $\mathrm{Ag}$ NPs against Candida albicans. Monteiro et al. (2011) evaluated the antifungal effect of silver colloidal nanoparticles against Candida albicans and Candida glabrata 
adhered cells and biofilms, and found that Ag NPs were more effective against adhered cells than pre-formed biofilms with the exception of Candida glabrata, which in both cases showed a reduction $\sim 90 \%$, and the particle size of Ag NPs and the type of stabilizing agent used did not interfere in the antifungal activity of Ag NPs against Candida biofilms (Monteiro et al. 2012). Recently, Silva et al. (2013) reported that silver nanoparticles showed a significantly greater effect on reducing Candida glabrata biofilm biomass compared with Candida albicans. Lately, spherical silver nanoparticles $(1 \mathrm{~nm})$ were reported to have a potent dose-dependent inhibitory effect on biofilm formation of Candida albicans, with an $\mathrm{IC}_{50}$ of $0.089 \mathrm{ppm}$ and $\mathrm{CC}_{50}$ of 7.03 ppm, mainly via cell wall disruption (Lara et al. 2015).

Antibiofilm properties of Ag NPs against multi-drug resistant (MDR) have been also investigated recently. Chemically synthesized Ag NPs $(20 \mu \mathrm{g} / \mathrm{mL})$ can inhibit the growth optimally and the formation of biofilm in the sensitive strain and the resistant strain Pseudomonas aeruginosa with an inhibition rate of $67 \%$ and $56 \%$, respectively (Palanisamy et al. 2014). Treatment of catheters with gum arabic capped-silver nanoparticles (GA-Ag NPs) at $50 \mu \mathrm{g} / \mathrm{mL}$ resulted in $95 \%$ inhibition of bacterial colonization against the MDR biofilm forming of Pseudomonas aeruginosa (Ansari et al. 2014). The Ag NPs (MIC 11.25 - $45 \mu \mathrm{g} / \mathrm{mL}$ ) coated surfaces also have effectively restricted biofilm formation of MRSA and methicillin resistance Staphylococcus epidermidis (MRSE) isolated from wounds, arrested the bacterial growth and prevent the glycocalyx formation (Ansari et al. 2015).

Green synthesis of NPs attract increasing attention of investigators recently 
because of the potential toxicity problem of chemical NPs. Green NPs are synthesized using non-toxic reducing agents like plant extracts, enzymes and microbial biomass. Biologically synthesized Ag NPs exhibited a potential antibiofilm activity on biofilms formed by Pseudomonas aeruginosa and Staphylococcus epidermidis (Kalishwaralal et al. 2010). Kumar and Sujitha (2014) showed that Kocuran-functionalized silver glyconanoparticles could inhibit the biofilm development by Staphylococcus aureus and Escherichia coli through the damage of intact cell architecture. Biogenic silver nanoparticles with a mean size of $\sim 6 \mathrm{~nm}\left(\right.$ Bio- $\mathrm{Ag}^{0-6}$ ) not only exhibited excellent antibacterial performance but also could control biofilm formation and induce detachment of the bulk of Pseudomonas aeruginosa biofilms leaving a small residual matrix (Zhang et al. 2014). Significant antimicrobial and antibiofilm effects against Pseudomonas aeruginosa, Shigella flexneri, Staphylococcus aureus, and Streptococcus pneumonia, have been observed at lowest concentration of Ag NPs synthesized with a novel plant extract of $A$. cobbe in combination with antibiotics, and significant enhancing effects for ampicillin and vancomycin against gram-negative and gram-positive bacteria, respectively (Gurunathan et al. 2014). A green starch-stabilized Ag NPs was shown to be more effective against gram-positive and gram-negative pathogens as compared with acid-fast bacteria, disrupted biofilm formation and exhibited better antibacterial activity compared to human cationic antimicrobial peptide LL-37 (Mohanty et al. 2012). Significant biofilm inhibition by ELE-Ag NPs synthesized by using aqueous leaf extract of Eucalyptus globulus (ELE) was observed in case of Staphylococcus aureus and Pseudomonas aeruginosa, 
272

273

274

275

276

277

278

279

280

281

282

283

284

285

286

287

288

289

290

291

292

293

respectively (Ali et al. 2015). The silicon tubes and polystyrene coverslips surfaces with biogenic Ag NPs using tea extract demonstrated efficient antibiofilm activity, via disrupting cell-cell adhesion in Staphylococcus aureus and Escherichia coli biofilm (Goswami et al. 2015).

Given these properties, there are many diverse applications for Ag NPs, including wound dressings, coatings on medical devices to prevent microbial colonization, substitution of antibiotics and surgical masks, impregnated textile fabrics, nanogels, and nanolotions (Ip et al. 2006; Leaper 2006; Li et al. 2006; Huh and Kwon 2011; Knetsch and Koole 2011).

\subsection{Titanium nanoparticles $\left(\mathrm{TiO}_{2} \mathrm{NPs}\right)$}

After the first report on a $\mathrm{TiO}_{2}$ application for the photocatalytic purification of water containing cyanide (Frank and Bard 1977), this material has been extensively used on a variety of applications and products including air and water pollution control systems and self-cleaning surfaces. When $\mathrm{TiO}_{2}$ is irradiated with near-UV light, this semiconductor exhibits strong photocatalytic oxidation, which is an advanced oxidation process for the removal of trace contaminants and microbial pathogens (Maness et al. 1999; Li et al. 2008b; Blecher et al. 2011; Huh and Kwon 2011; Qu et al. 2013; Hossain et al. 2014).

The photocatalytic antimicrobial activity of $\mathrm{TiO}_{2}$ is attributed to the production of ROS, including hydrogen peroxide $\left(\mathrm{H}_{2} \mathrm{O}_{2}\right)$, superoxide radical $(\mathrm{O} 2 \bullet-)$ and hydroxyl radicals $(\cdot \mathrm{OH})$, upon exposure to near-UV and UVA radiation (Choi et al. 2007b;

Hindi et al. 2009; Huh and Kwon 2011). When irradiated $\mathrm{TiO}_{2}$ is in close proximity to 
294

295

297

298

bacteria, the ROS damages membrane, DNA, and many other macromolecules of bacterial cells. Damaged membrane structure (Maness et al. 1999; Huh and Kwon 2011), OH radical forming (Benabbou et al. 2007; Hossain et al. 2014), Fenton reaction phenomenon (Gogniat and Dukan 2007), the oxidation/reduction of the intracellular coenzyme A (Markowska-Szczupak et al. 2011), and the physicochemical properties of $\mathrm{TiO}_{2}$ particles (Huang et al. 2000; Markowska-Szczupak et al. 2011), also contribute to microbe inactivation. There are two distinct phases during the destruction of a bacterial cell. In the initial phase, the oxidative damage of cell wall takes place, but cells still remain viable. As the photocatalysis progresses, the titanium dioxide particles cause deleterious oxidation processes leading to cell death (Huang et al. 2000; Desai and Kowshik 2009; Markowska-Szczupak et al. 2011). The kinetic data show that the cell wall damage takes place in less than 20 min, followed by the progressive damage of cytoplasmic membrane and intracellular components (Huang et al. 2000; Markowska-Szczupak et al. 2011). $\mathrm{TiO}_{2}$ NPs also have bactericidal effects in the absence of irradiation, suggesting that they use other antimicrobial mechanisms unrelated to photocatalytic ROS production, which is yet to be fully understood (Adams et al. 2006; Choi et al. 2007a).

Inactivation of microorganisms depends upon several factors, e.g., concentration of $\mathrm{TiO}_{2}$, type of microorganism, intensity and wavelength of light, degree of hydroxylation, $\mathrm{pH}$, temperature, availability of oxygen, and ROS retention time (Benabbou et al. 2007; Markowska-Szczupak et al. 2011; Hossain et al. 2014). Moreover, bacteria inactivation rate can be increased with increasing dosage of $\mathrm{TiO}_{2}$, 
316

317

light intensity and contact time (Hossain et al. 2014). Other studies reported $\mathrm{TiO}_{2} \mathrm{NPs}^{\prime}$ antimicrobial efficiency in the order of Escherichia coli $>$ Pseudomonas aeruginosa $>$ Staphylococcus aureus $>$ Enterococcus faecium $>$ Candida albicans and concluded that the order was mainly determined by the complexity and density of the cell membrane/wall (Kühn et al. 2003; Huh and Kwon 2011). Another study concluded that the diverse sensitivity of bio-particulates towards photocatalysis followed the following order: viruses $>$ gram-negative bacteria $>$ gram-positive bacteria $>$ yeasts $>$ filamentous fungi (Markowska-Szczupak et al. 2011). The $\mathrm{TiO}_{2}$ photocatalysis shows a great potential to kill bacteria, but the use of this process is limited to the environment with sufficient $\mathrm{UV}$ light. $\mathrm{TiO}_{2}$ doped by metals $(\mathrm{Ag}, \mathrm{Ni}, \mathrm{Pt}, \mathrm{Au}, \mathrm{Ag}, \mathrm{Cu}$, Rh, Pd) and oxides $\left(\mathrm{ZnO}, \mathrm{WO}_{3}, \mathrm{SiO}_{2}, \mathrm{CrO}_{3}\right)$ or non-metals $(\mathrm{C}, \mathrm{N}, \mathrm{S}, \mathrm{P})$ can improve visible light absorbance of $\mathrm{TiO}_{2}$ and increase its photocatalytic activity under UV irradiation (Li et al. 2008b; Markowska-Szczupak et al. 2011; Hossain et al. 2014). The addition of $\mathrm{Ag}$ to $\mathrm{TiO}_{2}$ was found to significantly enhance antimicrobial activity (Vamathevan et al. 2004; Reddy et al. 2007b).

According to recent studies, $\mathrm{TiO}_{2}$ also inactivates various microorganisms that are highly resistant to desiccation and UV radiation, which makes $\mathrm{TiO}_{2}$ a promising agent for improving hygiene, and product safety in food industry and cosmetics (Reddy et al. 2007b; Muranyi et al. 2010; Huh and Kwon 2011). For example, antibacterial effects of $\mathrm{TiO}_{2}$ on Lactobacillus acidophilus would also be used in orthodontic appliances, such as pit and fissure sealants, toothbrushes, dental implants, and screws (Choi et al. 2007b; Huh and Kwon 2011). 
$\mathrm{TiO}_{2}$ NPs have also been used as antibiofilm agent. Several researchers have demonstrated the antibiofilm activity of $\mathrm{TiO}_{2} \mathrm{NPs}$ against bacteria and fungi. Streptococcus mitis from the oral cavity causes endocarditis and other systemic infections. Khan and co-workers showed that $\mathrm{TiO}_{2}$ NPs can control the growth and biofilm formation activities of Streptococcus mitis ATCC 6249 and Ora-20, and increase in super oxide dismutase activity, suggesting its potential use as alternative antimicrobial agents for oral hygiene (Khan et al. 2016). Natarajan (2015) showed the antibiofilm property of Epoxy/Ag- $\mathrm{TiO}_{2}$ polymer nanocomposite coatings against Staphylococcus aureus and Escherichia coli under static conditions, and suggested that this property may be due to combined release of biocide, and photocatalytic activity. Lungu et al. (2014) synthesized two $\mathrm{Ag}-\mathrm{TiO}_{2}$ nanocomposites $(31.3 \pm 0.5$ $\mathrm{nm}$ and $23.4 \pm 0.4 \mathrm{~nm}$ ) and screened their antimicrobial activity. Results showed a good antibiofilm activity against several strains including Bacillus subtilis IC 12488, Staphylococcus aureus IC 13204, Escherichia coli IC 13147 and IC13529, Klebsiella pneumoniae 1204 and IC 13420, except MRSA 1307. $\mathrm{TiO}_{2}$ nanoparticles had effective antifungal properties at the concentration of $5.14,5.35 \mu \mathrm{g} / \mathrm{mL}$ for fluconazole susceptible and resistant strain of Candida albicans biofilms compared to fluconazole drug, respectively (Haghighi et al. 2013). Shirakawa et al. (2016) evaluated $\mathrm{TiO}_{2}$ coatings on biofilm formation on glass, which were exposed to the open atmosphere for 5 months in São Paulo city, and found that $\mathrm{TiO}_{2}$ coating inhibited the formation of fungal filaments, hence reduced overall biofilm cover.

\subsection{Zinc nanoparticles (ZnO NPs)}


Zinc nanoparticles ( $\mathrm{ZnO}$ NPs) are extensively used in a wide variety of

361

362

363

364

365

366

367

368

369

370

371

372

373

374

375

376

377

378

379

380

381

commercial products like food (Shi et al. 2014), textiles (Dastjerdi and Montazer 2010;

Petkova et al. 2014) and medicine (Rasmussen et al. 2010; Eshed et al. 2012). ZnO in

nanoscale has shown strong antimicrobial activities on a broad spectrum of microbes,

and great potential for microbial control and restriction of biofilm formation (Sawai et al. 2003; Applerot et al. 2012). The exact antimicrobial mechanism of ZnO NPs is still unknown. However, several studies have indicated that the formation of ROS is the main antimicrobial mechanism of $\mathrm{ZnO}$ NPs and clearly indicated that ZnO NPs or powders in aqueous solution can produce various ROS including $\mathrm{H}_{2} \mathrm{O}_{2}$ (Sawai et al. 1998; Yamamoto 2001; Zhang et al. 2008; Jalal et al. 2010; Gordon et al. 2011; Espitia et al. 2012; Shi et al. 2014; Padmavathy and Vijayaraghavan 2016). The generation of ROS and the disruption of cell membranes caused by ZnO NPs seemed to have bactericidal activity. In addition, other mechanisms for the antimicrobial activity of $\mathrm{ZnO}$ NPs have also been reported, such as the interaction of $\mathrm{ZnO}$ with the microbial cell membranes and the generation of damage on microbial surface (Zhang et al. 2007; Zhang et al. 2008; Xie et al. 2011), and release of $\mathrm{Zn}^{2+}$ as antimicrobial ions (Reddy et al. 2007a; Applerot et al. 2012; Padmavathy and Vijayaraghavan 2016). Several factors can affect the antimicrobial activity of $\mathrm{ZnO} \mathrm{NPs}$, including size (Zhang et al. 2007; Ohira et al. 2008; Palanikumar et al. 2014), surface area (Padmavathy and Vijayaraghavan 2016), concentration (Reddy et al. 2007a; Hossain et al. 2014; Padmavathy and Vijayaraghavan 2016), pH (Zhang et al. 2008; Hossain et al. 2014) and the presence of other antimicrobial agents (Dutta et al. 2010; Bhadra et 
382

383

384

385

386

387

388

389

390

al. 2011; Gordon et al. 2011). ZnO NPs are of relatively low cost and effective in size dependency against a wide range of microorganisms (Palanikumar et al. 2014). These include pathogens such as bacteria Klebsiella pneumoniae (Reddy et al. 2014), Listeria monocytogenes, Salmonella enteritidis (Jin et al. 2009), Streptococcus mutans, Lactobacillus (Kasraei et al. 2014), and Escherichia coli (Jin et al. 2009; Liu et al. 2009b), and fungi Botrytis cinerea and Penicillium expansum (He et al. 2011) with low toxicity to human cells (Reddy et al. 2007a). Furthermore, $\mathrm{ZnO}$ is currently listed as a "generally recognized as safe (GRAS)" material by the U.S. Food and Drug Administration and is used as food additive (Espitia et al. 2012; Shi et al. 2014). Many reports have indicated that ZnO NPs have better activity towards gram-positive bacteria than towards gram-negative bacteria (Jones et al. 2008; Xie et al. 2011). Tawale et al. (2010) justified the low inhibition rate of gram-positive bacteria Staphylococcus aureus compared with gram-negative Escherichia coli. The reason may probably be due to the difference of cell membrane structure. $\mathrm{ZnO}$ nanoparticles containing formulations have been utilized for external uses as antibacterial agents in lotions and ointments.

Several studies have investigated the antibiofilm activity of $\mathrm{ZnO}$ nanoparticles. It is a known fact that $\mathrm{ZnO}$ NPs are not stable when dispersed in water, therefore manufacturers use several surface modifying agents to increase the stability of $\mathrm{ZnO}$ NPs. A white appearance, UV-blocking properties, and ability to prevent biofilm formation make ZnO NPs suitable for fabric (Dastjerdi and Montazer 2010) and glass (Applerot et al. 2012) industries as coating materials designated for medical and other 
404

405

406

407

408

409

410

411

412

413

414

415

devices. ZnO NPs can effectively suppress biofilm formation of Pseudomonas aeruginosa (Dwivedi et al. 2014; Lee et al. 2014; Garcia-Lara et al. 2015; Hassani Sangani et al. 2015). ZnO NPs were found to markedly inhibit biofilm formation and the production of pyocyanin, pseudomona squinolone signal (PQS), pyochelin, and hemolytic activity of Pseudomonas aeruginosa without affecting the growth of planktonic cells, and the effect require the czc regulator CzcR (Lee et al. 2014). Applerot et al. (2012) showed that coating glass with ZnO NPs could inhibit biofilm formation for both Escherichia coli 1313 and Staphylococcus aureus 195, and that the pre-exposure to $\mathrm{ZnO}$-coated surfaces increased bacterial susceptibility to antibiotics, providing a versatile platform for a wide range of applications both in medical and industrial settings. Vaseeharan et al. (2015) have shown that the antibiofilm activity of chitosan-ZnO composite against the Vibrio parahaemolyticus and Bacillus lechiniformis bacteria isolated from aquatic environment at a concentration of $40 \sim$ $60 \mu \mathrm{g} / \mathrm{mL}$. Gold-based zinc oxide nanostructures (Au@ZnO) were shown to have inhibition of microbial growth and biofilm by disruption of cellular functions and biofilms via ROS-dependent generation of superoxide anion radical (Gholap et al. 2016). $\mathrm{ZnO}$ /polyacrylamide nanocomposite (ZnO/PAM.NC10) exhibited antibiofilm activity against Bacillus subtilis and Escherichia coli (Morsi et al. 2016).

\subsection{Other metal NPs}

Several other metal NPs were also used for studying the biofilm dynamics. Ferromagnetic NPs has been reported cleaved macromolecules presented in biofilms in the presence of hydrogen peroxide and acted like biofilm-degrading enzymes (Gao 
426

427

428

429

430

431

432

433

434

435

436

437

438

439

440

441

442

443

444

445

446

447

et al. 2014; Thukkaram et al. 2014). Surface of wound dressing fibers coated with the obtained nanofluid, which was composed of functionalized magnetite nanoparticles and Satureja hortensis essential oil, strongly inhibited Candida albicans adherence and subsequent biofilm development comparing with regular uncoated materials (Anghel et al. 2013). Tripathy et al. (2016) coated glass surfaces with quanta-CuO, and found the surface showed a very high contact bacteria-killing capacity towards Staphylococcus aureus and Escherichia coli as a result of contact killing and/or copper ion release killing mechanisms. $\mathrm{Cu}_{2} \mathrm{O}-\mathrm{NPs}$ exerted their action by disruption of the bacterial cell membrane and can be used as effective antistaphylococcal and antibiofilm agents in diverse medical devices (Singh et al. 2015a). Eshed et al. (2013) coated teeth with $\mathrm{MgF}_{2}$ NPs layer, and the coating successfully inhibited Streptococcus mutans biofilm formation by over $60 \%$. The $\mathrm{MgF}_{2} \mathrm{NPs}$ could attach and penetrate into the cells, cause disruption in the membrane and induce membrane lipid peroxidation, and once internalized could interact with chromosomal DNA. Surfaces coated with $\mathrm{MgF}_{2}$ NPs effectively restricted biofilm formation of Escherichia coli C600 and Staphylococcus aureus FRF1169 (Lellouche et al. 2009). The Se NPs (10-50 nm) biosynthesized by Khiralla and El-Deeb (2015) has showed sharp effect as an antibiofilm agent against Enterococcus faecalis, Staphylococcus aureus, Escherichia coli O157:H7, Salmonella typhimurium and Salmonella enteritidis where they lost their ability to form biofilm (100\%). The antibiofilm activities of gold NPs (Sathyanarayanan et al. 2013; Castillo-Martínez et al. 2015; Nithya and Jayachitra 2016), calcium fluoride NPs (Kulshrestha et al. 2016) and other 
mental NMs have also been reported.

$\mathrm{Ag}, \mathrm{TiO}_{2}$ and $\mathrm{ZnO}$ NPs have some similarities such as their inorganic nature, similarities in the variety of synthesis methods used and the similarities in their toxicity to the environment. However, there are some differences in bioavailability, applications and regulations shown in Table 4. Despite the controversies and ongoing debates, Ag NMs are perhaps the most promising antibacterial metal NMs. The strong antibiofilm effect of Ag NPs is indisputable.

\subsection{Chitosan and chitosan based nanocomposites}

Chitosan, a copolymer of $\mathrm{N}$-acetylglucosamine and glucosamine derived by deacetylation of chitin compound (Tikhonov et al. 2006), has been studied extensively throughout the world in due of its broad-spectrum antimicrobial activity (Tikhonov et al. 2006; Friedman et al. 2013; Ibrahim et al. 2014). The antimicrobial activity of chitosan can be increased by packaging chitosan into NPs (Qi et al. 2004; Blecher et al. 2011; Friedman et al. 2013). They are promising as low-cost and low-tech disinfectants, particularly in developing countries (Li et al. 2008b).

The exact mechanism of the antimicrobial action of chitin, chitosan, and their derivatives is still unknown, however, different mechanisms have been proposed. One mechanism is the positively charged chitosan molecules interacting with the negatively charged bacterial surface to cause agglutination, thus increasing membrane permeability, which eventually induces a rupture and leakage of intracellular components (Qi et al. 2004). According to another proposed mechanism, chitosan could chelate with trace metals or essential nutrients so as to inhibit enzyme activities 
470

471

472

473

474

475

476

477

478

479

480

481

482

483

484

485

486

487

488

489

490

491

and the microbial growth (Qi et al. 2004; Huh and Kwon 2011). It has also been

proposed that when chitosan is liberated from the cell wall of fungal pathogens by the host's hydrolytic enzymes, it penetrates to the nucleus of fungi and inhibits mRNA and protein syntheses by binding to microbial DNA (Rabea et al. 2003).

The antimicrobial activity of chitosan is influenced by a number of factors that include the type of chitosan, the degree of chitosan polymerization, molecular weight, solvent, pH, its charges and solubility (Chung 2003; Rabea et al. 2003; Qi et al. 2004;

Don et al. 2005; Fernandes et al. 2010; Tavaria et al. 2013). Chitosan, however, exhibits its antimicrobial activity only under acidic condition because of its poor solubility above $\mathrm{pH}$ 6.5. Thus, water-soluble chitosan derivatives (soluble in both acidic and basic physiological circumstances) may be good candidates as a biocide (Rabea et al. 2003; Je and Kim 2006).

Chitosan and chitosan based nanocomposites exhibit high antimicrobial activity as their unique character. NPs synthesized with chitosan and alginate demonstrated a direct antimicrobial activity in vitro against Propionibacterium acnes, the bacterium linked to the pathogenesis of acne, probably through inducing the disruption of the cell membrane (Friedman et al. 2013). Chitosan NPs and copper-loaded NPs could inhibit the growth of Escherichia coli, Salmonella choleraesuis, Salmonella typhimurium, and Staphylococcus aureus, and the exposure of Salmonella choleraesuis to the chitosan NPs led to the disruption of cell membranes and the leakage of cytoplasm (Qi et al. 2004). Nanocomplexes prepared from chitosans with high MW showed a low antimicrobial effect (20 $25 \%$ of cells damaged), whereas 
492

493

494

495

496

497

498

499

500

501

502

503

504

505

506

507

508

509

510

511

512

513

those prepared from low-MW chitosans showed high antimicrobial effect (>95\% of cells damaged) on Streptococcus mutans (de Paz et al. 2011). The ability of chitosan as both a complexing and stabilizing agent is usually utilized to form uniformly deposited NMs with other NPs. Nanostructured chitosan (CS) and a chitosan-Zn (ZnCS) coated textiles showed antimicrobial activity towards Enterococcus faecalis and Escherichia coli. A more than two-fold increase of the antibacterial activity of $\mathrm{Zn}-\mathrm{CS}$ NPs coated textiles was detected as compared to the fabrics treated with the sonochemically synthesized CS NPs alone (Perelshtein et al. 2013).

Chitosan and chitosan based nanocomposites are also potential antibiofilm agents. Surfaces coated with the naturally-occurring polysaccharide chitosan significantly resisted biofilm formation by Staphylococcus epidermidis, Staphylococcus aureus, Klebsiella pneumoniae, Pseudomonas aeruginosa and Candida albicans with reductions in biofilm viable cell numbers ranging from $95 \%$ to 99.9997 \% (Carlson et al. 2008). Chitosan-Ag NPs exhibited excellent antibiofilm activity against Pseudomonas aeruginosa, whereas treatment of Staphylococcus aureus with the same concentration of chitosan showed no significant inhibition in biofilm formation (Prajna Jena 2012). Wei et al. (2009) found that films with chitosan-based silver nanoparticles exhibited both fast and long-lasting antibacterial effectiveness against Escherichia coli. Chitosan-based zinc oxide nanoparticles showed significant inhibition of growth and biofilm formation against Micrococcus luteus and Staphylococcus aureus (Dhillon et al. 2014). Tan et al. (2015) noted that the $\beta$-N-acetyl-glucosaminidase (DspB) immobilized on carboxymethyl chitosan 
514

515 nanoparticles (CMCS) showed increased antibiofilm activity against Staphylococcus aureus, Staphylococcus epidermidis, and Actinobacillus actinomycetemcomitans due to the improvement of the enzyme stability and the antibiofilm activity of CMCS nanoparticles. Synthesized cefotaxime loaded chitosan based nano-antibiotics demonstrated broad-spectrum antibiofilm and anti-pathogenic activity against clinical isolates of multi drug resistant Klebsiella pneumoniae, Pseudomonas aeruginosa, Escherichia coli, and methicillin resistant Staphylococcus aureus (Jamil et al. 2016). Ferulic acid encapsulated chitosan nanoparticles (FA-CSNPs) reduced Candida albicans biofilm cell viability up to $22.5 \%$, and induced disruption of biofilm architecture, suggesting that it could be used as an effective alternative to the conventional antifungal therapeutics (Panwar et al. 2016). Biodegradable chitosan nanoparticles (CSNPs) enhanced the efficacy of methylene blue (MB)-antimicrobial photodynamic inactivation (APDI), it may be due to the disruption of biofilm structure by polycationic CSNPs and subsequently deeper and higher penetration of MB into the biofilms (Darabpour et al. 2016). Bioactive polymeric chitosan nanoparticles functionalized with rose-bengal (CSRBnp) showed significant antibacterial activity, reduced viability of Enterococcus faecalis biofilms and disruption of biofilm structure by adhering to bacterial cell surface, increasing the permeability of the membrane and lysing the cells subsequent to photodynamic treatment (Shrestha et al. 2014).

Chitosan has been shown to be useful in many different areas, and specifically in agriculture, wastewater treatment, food, and biomedicine fields (Rabea et al. 2003; Qi 
536

537

538

539

540

541

542

543

544

545

546

547

548

549

550

551

552

553

554

555

556

557

et al. 2004; Fernandes et al. 2008; Li et al. 2008b; Tin et al. 2009). It has several advantages over other antimicrobials, as indicated by high antimicrobial activity, by broad spectrum of activity against bacteria, viruses and fungi, and by a low toxicity on mammalian cells. However, chitosan is an effective antimicrobial only at acidic $\mathrm{pH}$ and depends on the availability of charged amino groups (No et al. 2002; Rabea et al. 2003). The preparation of water-soluble derivatives of chitosan may eventually overcome this limitation.

\subsection{Carbon nanotubes (CNTs)}

Carbon nanotubes (CNTs) are cylindrical nanostructures made of pure carbon atoms covalently bonded in hexagonal arrays (Hyung et al. 2007). They are increasingly being assessed for use in water purification owing to their high surface area, antimicrobial activity, electronic properties, and ease of functionalization ( $\mathrm{Li}$ et al. 2008b; Brady-Estévez et al. 2008, 2010). Single-walled nanotubes (SWCNTs) are a single pipe with a diameter in the range of $1 \sim 5 \mathrm{~nm}$, while multi-walled tubes (MWCNTs) have several nested tubes with lengths varying from $100 \mathrm{~nm}$ to several tens of micrometers. Early studies indicated profound cytotoxicity of CNTs in alveolar macrophage. Presented here in the order of its toxicity are: SWCNTs $>$ MWCNTs $>$ quartz $>\mathrm{C}_{60}$. Surprisingly, the effect of CNTs has not received much attention, probably because of the poor aqueous dispersion of pure CNTs (Li et al. 2008b). Recently, it was demonstrated that surfactants or polymers could be used to facilitate the aqueous disparity of CNTs (Hyung et al. 2007).

The CNTs' antimicrobial mechanism is not fully understood. Previous studies on 
558 CNTs' cytotoxicity have concluded that membrane stress (i.e., direct CNTs bacteria 559 contact resulting in membrane perturbation and the release of intracellular contents) 560 was the primary cause of cell death (Kang et al. 2007; Arias and Yang 2009; Liu et al. 561 2009a; Obraztsova et al. 2009). Others suggest that oxidative stress (Kang et al. 2008; 562 Aslan et al. 2010; Rodrigues and Elimelech 2010) and CNTs electronic structure 563 (Vecitis et al. 2010) also play key roles. A three-step SWCNT antimicrobial 564 mechanism has been proposed, which involves (i) initial SWNT-bacteria contact, (ii) 565 membrane perturbation, and (iii) electronic structure-dependent bacterial oxidation 566 (Vecitis et al. 2010). The antimicrobial activity of CNTs is dependent on a number of 567 factors, including size (Kang et al. 2008), electronic structure (Vecitis et al. 2010), 568 surface (Arias and Yang 2009), length (Yang et al. 2010), and surfactant solutions 569 (Dong et al. 2012).

570 Antimicrobial activity of CNTs requires direct contact between CNTs and target 571 microorganisms (Kang et al. 2007; Li et al. 2008b). Recent work, however, has shown 572 scalable applications that use low-cost and widely available CNTs for inactivation of 573 microbes. Inclusion of oxidized single-wall (O-SWCNTs) or multi-wall CNTs 574 (O-MWCNTs) were reported to cause polymer nanocomposites (PNCs) surfaces to 575 exhibit antimicrobial properties towards Pseudomonas aeruginosa (Goodwin Jr et al. 576 2015). The MWCNTs-nisin composite showed up to 7-fold higher antimicrobial 577 property than pristine MWCNTs against Escherichia coli, Pseudomonas aeruginosa, 578 Staphylococcus aureus and Bacillus subtilis (Qi et al. 2011). While the 579 MWCNT-cefalexin composite showed 2-fold higher antimicrobial property than 
580

581

582

583

584

585

586

587

588

589

590

591

592

593

594

595

596

597

598

599

600

601

pristine MWCNTs against Staphylococcus aureus and Bacillus subtilis (Qi et al. 2012). Escherichia coli and Staphylococcus epidermidis viability and metabolic activity were significantly diminished in the presence of SWCNTs-polymer poly (lactic-co-glycolic acid) (PLGA), and up to $98 \%$ of bacteria died within one hour on SWCNTs-PLGA versus $15-20 \%$ on pure PLGA (Aslan et al. 2010).

CNTs coatings can significantly prevent biofilm formation. The thin layer of CNTs can effectively remove bacteria by size exclusion, and the retained bacteria are largely inactivated by CNTs within hours (Brady-Estévez et al. 2010). The effects of SWCNTs and MWCNTs on biofilm formation from Bacillus anthracis spores were investigated by Dong and colleagues (Dong et al. 2014). Their results showed that nisin coating on MWCNTs sheets decreased surface hydrophobicity, reduced spore attachment, and reduced the germination of attached Bacillus anthracis spores by 3.5 folds, and further inhibited the subsequent biofilm formation by $94.6 \%$ compared to that on uncoated MWCNTs sheet (Dong et al. 2014). In another study, $200 \mu \mathrm{g} / \mathrm{mL}$ SWCNTs decreased the germination of attached spores by $93.14 \%$, completely inhibiting subsequent biofilm formation (Dong and Yang 2014). MWCNTs-nisin composite had a dramatically improved capability to prevent biofilm formation both on a deposited film and in suspension, and the MWCNTs-nisin deposit film exhibited a 100-fold higher antibiofilm property than the MWCNTs deposit film (Qi et al. 2011). Analogously, MWCNTs-cefalexin composite film effectively inhibited cell adhesion (Qi et al. 2012). Covalent binding of SWCNTs to polyamide membranes were observed to achieve up to $60 \%$ inactivation of bacteria attached to the membrane 
602

603

604

605

606

607

608

609

610

611

612

613

614

615

616

617

618

619

620

621

622

623

within $1 \mathrm{~h}$ of contact time, suggesting the potential of covalently bonded SWNTs to delay the onset of membrane biofouling during operation (Tiraferri et al. 2011). SWCNTs-coated substratum had 10 times less biofilm colonization and biomass production of Escherichia coli K12 than a control substratum without SWCNTs (Rodrigues and Elimelech 2010).

In addition, CNTs-based filtration technology catches some attention. Kang et al. (2007) prepared a SWCNTs-coated filter and observed $87 \%$ reduction of the Escherichia coli cells on the SWCNTs-coated filter after the 60 min incubation. A poly vinylidene fluoride (PVDF) membrane coated with a thin layer of SWCNTs for water purification showed effective inactivation of Escherichia coli (Brady-Estévez et al. 2008, 2010). Unlike conventional filters, CNTs filters can be cleaned repeatedly to regain their full filtering efficiency (Srivastava et al. 2004; Kang et al. 2007; Brady-Estévez et al. 2008). Additional advantages of the CNTs filters include ease of production, gravity-driven or low-pressure operation, cytotoxicity towards microbes, high portability (Srivastava et al. 2004; Kang et al. 2007; Brady-Estévez et al. 2008).

With a small intermittent voltage $(2 \sim 3 \mathrm{~V})$, MWCNTs can directly oxidize attached bacteria and lead to inactivation in seconds. The applied electric potential also enhances viral transport to the anodic CNTs. Such CNTs filters can be used as high performance point-of-use (POU) devices for water disinfection with minimal to no power requirement (Vecitis et al. 2011; Rahaman et al. 2012). These benefits provide incentive for continued development of CNTs-based filtration technology for water treatment and other separation processes. However, it is important to recognize that 
624 other complex solution chemistry and the presence of foulants in source water may 625 impact CNTs filters performance.

626 As we explore opportunities for leveraging the unique properties of CNTs for 627 water purification applications, it is critical to consider simultaneously the potential 628 risks of incorporating these advanced materials in drinking water production. The 629 risks of nanomaterial exposure to humans are a function of both exposure and toxicity. 630 Application of the CNTs filters to drinking water treatment will require appropriate 631 designs that minimize human and environment exposure by immobilizing the CNTs in 632 the filter. As we develop functional applications of NMs in water treatment, we will 633 need to monitor the lifespan release of NMs to ensure human health and filter 634 durability. Although CNTs have some adverse effects on human health and the 635 environment, further research can increase its benefit and decrease its unfavorable 636 effects.

637

638

639

640

641

642

643

644

645

\subsection{Fullerenes}

Fullerenes are soccer ball-shaped molecules composed of carbon atoms $\left(\mathrm{C}_{60}, \mathrm{C}_{70}\right.$, etc.), and, when derivatized with functional groups, they become soluble and show antibacterial effects (Tsao et al. 2002; Tegos et al. 2005; Brant et al. 2006). In particular, numerous techniques have been developed for creating stable aqueous suspensions for fullerene with a large range of sizes (Fortner et al. 2005; Duncan et al. 2007; Lyon et al. 2006). The $\mathrm{nC}_{60}$ NPs are noted for their potent and broad antibacterial activity (Lyon et al. 2006; Li et al. 2008b).

The antimicrobial mechanism for fullerenes is still under debate. The debatable 
646

647

648

649

650

651

652

653

654

655

656

657

658

659

660

661

662

663

664

665

666

667

antibacterial mechanism for $\mathrm{nC}_{60}$ includes photocatalytic $\mathrm{ROS}$ production that is responsible for the membrane damage in eukaryotic cells (Sayes et al. 2005; Markovic et al. 2007; Lyon et al. 2008c). However, studies on $\mathrm{nC}_{60}$ assert that antibacterial activity is ROS-independent oxidative stress (Fang et al. 2007; Lyon et al. 2008c). Other possible mechanisms have also been reported, including effect on respiratory chain, disruption of the cell membrane structure (Tsao et al. 2002; Cataldo and Da Ros 2008), interaction with membrane lipids and intercalation into them (Tegos et al. 2005; Cataldo and Da Ros 2008; Deryabin et al. 2014; Dizaj et al. 2015).

The antimicrobial activity of fullerene is also affected by the size and surface area of it (Dizaj et al. 2015), the type of functional group used (Li et al. 2008b; Deryabin et al. 2014). Several previous reports demonstrated that cationic derivatives showed the best antibacterial effect on Escherichia coli and Shewanella oneidensis, while the anionic derivatives were almost ineffective (Cataldo and Da Ros 2008; Nakamura and Mashino 2009; Deryabin et al. 2014). This could be owing to the strong interactions of negatively charged bacteria with the cationic fullerenes (Nakamura and Mashino 2009).

Fullerenes have antimicrobial and antibiofilm activity against various microorganisms. Although pristine fullerene $\mathrm{C}_{60}$ demonstrated no antimicrobial activity, fullerenols $\left(\mathrm{C}_{60}(\mathrm{OH})_{12}, \mathrm{C}_{60}(\mathrm{OH})_{36} \cdot 8 \mathrm{H}_{2} \mathrm{O}\right.$, and $\left.\mathrm{C}_{60}(\mathrm{OH})_{44} \cdot 8 \mathrm{H}_{2} \mathrm{O}\right)$ exhibited good antimicrobial activity against Propionibacterium acnes, Staphylococcus epidermidis, Candida albicans, and Malassezia furfur. In particular, $\mathrm{C}_{60}(\mathrm{OH})_{44}$ exhibited a strong and wide-ranging antimicrobial activity comparable to that of 
668

669

670

671

672

673

674

675

676

677

678

679

680

681

682

683

684

685

686

687

688

689

catechin via inhibition of microbial cell growth and not via bactericidal activity (Aoshima et al. 2009). Studies reported that the employed derivative was able to inhibit environmental bacteria after photo irradiation (Cataldo and Da Ros 2008;

Deryabin et al. 2014). Tegos et al. (2005) demonstrated that cationic fullerenes with hydrophilic groups, after photo irradiation, showed a broad-spectrum antimicrobial activity and more than $99.99 \%$ of bacterial and fungal cells were rapidly killed. Mizuno et al. (2011) reported that cationic-substituted fullerene derivatives that possessed either basic or quaternary amino groups were highly effective as antimicrobial photo sensitizers (PS) against Staphylococcus aureus, Escherichia coli and Candida albicans. Zhang et al. (2015) have reported that cationic fullerene and potassium iodide potentiated the antimicrobial photodynamic inactivation against Acinetobacter baumannii, methicillin-resistant Staphylococcus aureus and Candida albicans. Encapsulated $\mathrm{C}_{60}$ can still exert antimicrobial properties in water, which might be more applicable due to the flexibility of the encapsulation. Both fullerols and encapsulated fullerenes can be considered for potential disinfection applications (Lyon et al. 2006; Li et al. 2008b). Alekseeva et al. (2014) found that the polystyrene/fullerene composite films manifest bacteriostatic and fungistatic effect. Ballatore and coworkers evaluated the photodynamic inactivation of bacteria of novel electrogenerated porphyrin-fullerene $\mathrm{C}_{60}$ polymeric films, and results showed the film was an interesting and versatile photodynamic active surface to eradicate bacteria (Ballatore et al. 2015). Fullerene $\mathrm{C}_{60}$ nanoparticles, introduced as an aqueous suspension, had size-dependent effects on soil bacterial community composition in 
690

691

692

693

694

695

696

697

698

699

700

701

702

703

704

705

706

707

708

709

710

711

the low organic matter system (Tong et al. 2016).

\section{Barriers of antimicrobial NMs for microbial control and biofilm formation}

While NMs hold significant promise for microbial control and biofilm formation, significant barriers stand between some of these promises and their delivery. Issues such as technical hurdles, cost effectiveness and potential environmental and human risk must be addressed.

\subsection{Technical hurdles}

Although nanotechnology enabled microbial control have shown great promise in laboratory studies, their readiness for commercialization vary widely. Some are already on the market, while others require further research before they can be considered for full-scale applications. Because most studies on antimicrobial activities of NMs have been conducted in relatively simple and clean environment, the sustainability of their antimicrobial activities in natural or complicated solutions is unclear. Adsorption onto geosorbents, and coating by natural organic matter have been shown to reduce toxicity of $\mathrm{nC}_{60}$ on bacteria ( $\mathrm{Li}$ et al. 2008a). When coated on surfaces to prevent microbial attachment and biofilm formation, antimicrobial nanoparticle coatings may rapidly lose their effectiveness due to adsorption of extracellular polymeric material and occlusion by precipitating debris (Lyon et al. 2008b).

Another challenge in efficient application of antimicrobial NMs in preventing microbial attachment and biofilm formation is dependent upon the dispersion and retention of NMs and the sustainability of antimicrobial activity. While NPs provide 
712

713

714

715

716

717

718

719

720

721

722

723

724

725

726

727

728

729

730

731

732

733

very high specific surface area, which is a primary reason for their high reactivity, the aggregation in water negates this benefit. NPs such as $\mathrm{TiO}_{2}$ aggregate severely when added to water. Although very stable in pure water, coagulation of $\mathrm{nC}_{60}$ can be induced by salt (Lyon et al. 2008a). The application of NPs as an effective antimicrobial agent should not cause microbial resistance even after long-term usage. However, there have been reports on bacterial resistance to antimicrobial compounds (Cloete 2003; Davies and Davies 2010), such as, silver (Silver et al. 2006), chromium compounds (Ramírez-Díaz et al. 2008), quaternary ammonium compounds (Sundheim et al. 1998) and antibiotics (Fisher et al. 2005). Another concern is that a widespread usage of silver NPs (e.g. as a component of disinfectants) might lead to silver-resistant bacterial strains (Markowska et al. 2013).

In addition, to date, little is known about the occurrence, fate and toxicity of NPs.

The limitations in our knowledge are partly due to the lack of methodology for the detection and characterization of engineered NPs in complex matrices, i.e. water, soil or food. Some reviews have provided an overview on this topic (Tiede et al. 2008; da Silva et al. 2011), but few techniques can detect NMs in complex aqueous matrices and they are expensive and with many limitations. Future work should focus on addressing these challenges. NMs also can be immobilized on various platforms such as resins and membranes to avoid further separation. However, current immobilization techniques usually result in significant loss of treatment efficiency. Further research is needed to develop simple, low-cost methods to immobilize NMs without significantly impacting its performance. For magnetic NPs/nanocomposites, 
734

735

736

737

738

739

740

741

742

743

744

745

746

747

748

749

750

751

752

753

754

755

low-field magnetic separation is a possible energy-efficient option.

\subsection{Cost effectiveness}

Broad acceptance of novel water and wastewater treatment nanotechnologies depends on both their performance and affordability. Most nanotechnology based treatment options are high-performance enabling more efficient treatment, but their costs are currently high. This represents a significant but not insurmountable barrier. The need to treat increasingly complex contaminant mixtures and produce higher quality water at lower cost is pushing the boundaries of current treatment paradigms.

A considerable fraction of the nanomaterial production cost is related to separation and purification. Prices of research-grade NMs have remained relatively constant over the past decade and they did not drop significantly without increased demand and production scale-up. Note that, the feasibility of using NMs for water treatment can be enhanced by producing NMs of lower purity. For example, amino-fullerene photocatalysts made with fullerene soot rather than ultrapure $\mathrm{C}_{60}$ (a cost savings of $90 \%$ ) exhibited a minimal (<10\%) loss of effectiveness (Lee et al. 2010). Furthermore, long-term reusability of NMs enhances their cost-effectiveness. Encouraging examples include photocatalysts that retain activity through multiple reuse cycles (Lee et al. 2010) and regeneration of nanoadsorbents (Roberts et al. 2007) and magnetically separable multifunctional NMs (Yavuz et al. 2006).

\subsection{Potential toxicity}

Retention of NMs is critical not only because of the cost associated with the loss of NMs, but also, and more importantly, because of the potential impacts of NMs on 
756

757

758

759

760

761

762

763

764

765

766

767

768

769

770

771

772

773

774

human health and ecosystems. Our understanding of the potential human health and environmental implication of NMs is improving with the increasing number of nanotoxicity studies in the past few years. For example, the non-toxicity of nanostructured silver on membrane surface has been proven by growing human fibroblasts at various concentrations of silver NPs (Wen et al. 2007). Skin-innoxiousness of nanostructured silver colloidal solution especially in the case of smaller NPs has been demonstrated via the skin irritation test performed on rabbits (Lee and Jeong 2005). Silver is mentioned as an almost non-toxic to mammalian systems (Dastjerdi and Montazer 2010). Incubation of astrocyte primary cultures with magnetic iron oxide NPs has also demonstrated that the particles do not induce any acute damage to these brain cells (Geppert et al. 2009). However, another report implied that Ag NPs at high doses could have genotoxic and cytotoxic effects on human cells (Jena et al. 2012). In vitro experiments, Park and coworkers showed that the potency of silver NPs to induce cell damage, compared to silver ions, is cell type and size-dependent (Park et al. 2011a). As we know, prolonged exposure to soluble silver-containing compounds may produce an irreversible pigmentation in the skin (argyria) and the eyes (argyrosis), in addition to other toxic effects, including organ damages (e.g., liver and kidney), irritation (e.g., eyes, skin, respiratory, and intestinal tract), and changes in blood cell counts (Drake and Hazelwood 2005).

About 30 organizations from different countries are investigating the potential risks of nano-structured materials with the aim of developing appropriate test methods to assess their possible side-effects on the human health and the environment. Several 
778

779

780

781

782

783

784

785

786

787

788

789

790

791

792

793

794

795

796

797

798

799

articles have summarized the potential toxicity and environmental management of NMs (Dreher 2004; Auffan et al. 2009; Bystrzejewska-Piotrowska et al. 2009; Levard et al. 2012). The toxic effect of inhalation of CNTs has been shown in vivo testing (Dawson 2008). Potential CNTs health hazards, because of its similarity to asbestos fibers, have also been warned (Service 1998). Generally, ZnO powders or NPs are bio-safe within a certain range, but may become hazardous at higher concentrations. $\mathrm{ZnO}$ NPs have also been shown to reduce the viability of human $\mathrm{T}$ cells at a high concentration of $5 \mathrm{mM}$ (Reddy et al. 2007a; Qu et al. 2012). Bulk $\mathrm{TiO}_{2}$ particles (> $100 \mathrm{~nm}$ ) are known to be harmless to humans and animals. High dosage of inhalation nano- $\mathrm{TiO}_{2}$ can act as a pulmonary inflammation agent and be harmful for body tissues (Geppert et al. 2009). Until we fully understand the short- and long- term toxicity, which need more time and more investigation, people should be cautious about the potential toxicities of nano-structured materials.

\section{Critical research needs}

As discussed above, significant limitations exist on the use of NMs for microbial control and biofilm formation. This calls for more researches to further assess their applicability and to address their limitations.

First, the performance of various nanotechnologies under natural environmental conditions needs to be tested. Future studies need to be done under more realistic conditions to assess the applicability and efficiency of different nanotechnologies as well as to validate nanomaterial enabled sensing technologies. Secondly, the long-term efficacy of these nanotechnologies is largely unknown as most laboratory 
800

801

802

803

804

805

806

807

808

809

810

811

812

813

814

studies have been conducted over relatively short periods of time. Research addressing the long-term performance of nanotechnologies in microbial control is of great need.

There are currently two approaches to address the cost issue. One proposed approach is to use low purity NMs without significantly compromising efficiency as much of the production cost is related to separation and purification (Qu et al. 2012). Low-cost NMs should be explored for potential applications in microbial control. Alternatively, the cost-effectiveness can be improved by retaining and reusing NMs. Effective and reliable methods are needed to anchor the NPs to reactor surfaces or the selective layer of filtration membranes, or to separate and retain suspended NPs in order to reduce costs associated with premature material loss and to prevent potential human health and environmental impacts. This includes developing better surface coating techniques perhaps through nanoparticle surface functionalization, minimizing membrane fouling by the nanomaterial suspension, and impregnating NPs into filter packing materials, e.g. granular activated carbon, or ion exchange resins. Advances in these areas may allow incorporation of antimicrobial NMs into microbial control.

database available for their bulk counterparts and shared constituents. However, allotropic NMs such as fullerenes and CNTs do not have bulk counterparts precluding such comparisons and suggesting the need for more careful toxicity studies. In a broad prospective, risk assessment should consider every stage in the life cycle of NMs 
822 (Eckelman et al. 2012). Minimizing risks to public and environmental health could be

823 achieved by curtailing potential exposure through nanoparticle immobilization onto

824 reactor surfaces or support media. This may have the ancillary benefit of reduced

825 nanoparticle aggregation and improved activity (Lee et al. 2010). For NPs that release

826 toxic metals (e.g., nanostructured $\mathrm{Ag}$ and metallic quantum dots), it is important to

827 control their dissolution, e.g., by using stabilizing coatings or optimizing nanoparticle

828 shape and size. Depending on the application scenario, barrier technologies (e.g.,

829 membranes and magnetic separation) may be used to recover nanoparticle and prevent

830 their release (Qu et al. 2012). Risk minimization should also consider the design of

831 safer NMs using constituents that are inherently nonhazardous. A significant

832 challenge facing this strategy is to reduce toxicity without stifling nanomaterial

833 performance.

834 It is important to note that most of the disinfection processes of nanomaterial are

835 based upon the results of planktonic tests. However, such tests do not mimic the

836 behavior of biofilm cells and can be highly ineffective when applied to control

837 biofilms. Due to the limited efficacy of nanomaterial in preventing or treating biofilms,

838 a number of alternative strategies need to be devised. Another strategy for biofilm

839 control that is currently receiving serious consideration is based on interference with

840 bacterial cell-to-cell communication (quorum sensing). Because quorum sensing plays

841 a vital role in infections caused by human, animal and plant pathogens, the

842 identification of mechanisms that disrupt this system is a hot topic in microbiology.

843 Quorum sensing inhibitors are likely to be effective in controlling bacterial infections, 
844 while having no effect on human cells (Defoirdt et al. 2013; Markowska et al. 2013).

845 It is conceivable that quorum sensing inhibition may represent a natural, widespread, 846 antimicrobial strategy with significant impact on biofilm formation (Dong et al. 2002;

847 Simões et al. 2010). Some NMs have been reported to have anti-quorum sensing 848 (anti-QS) activity, such as $\mathrm{AgCl}-\mathrm{TiO}_{2}$ nanoparticles (Naik and Kowshik 2014), silver 849 nanowires (Wagh et al. 2013), mycofabricated biosilver nanoparticles (Singh et al. 850 2015c), spice oil nanoemulsions (Venkadesaperumal et al. 2016), Swarna-based 851 herbo-metallic colloidal nano-formulation (Singh et al. 2015b). A good understanding 852 of the cell-cell signaling phenomenon of bacteria such as Listeria monocytogenes can 853 be used to control the biofilm formation process by the identification of products that 854 can act as quorum sensing antagonists (Simões et al. 2009, 2010). This property can 855 lead to the development of new and efficient natural products for biofilm control in 856 our future study.

\section{5. Summary}

858 Microbial control in food, biomedical, natural environment (especially aquatic 859 environment) and industrial processing aims to reduce/eradicate microbes and their 860 activity, and to prevent/control the formation of biological deposits on the process 861 equipment. Metal, natural compound-based and carbon-based nanoparticle types have 862 shown tremendous potential as bactericidal and fungicidal elements, demonstrating 863 their potential as efficient antimicrobials in medical and environmental issues. Despite 864 numerous studies conducted over the last decade there are still considerable gaps in 865 our knowledge about the antimicrobial properties of NPs. Furthermore, the precise 
866

867

868

869

870

871

872

873

874

875

876

877

878

879

880

881

882

883

884

885

886

887

basis of their antimicrobial activity has yet to be defined. Nonetheless, the strong anti-bacterial effect of NPs is indisputable. Much more needs to be learned about the impact of antimicrobial NMs on microbial biofilms and their recovery responses to damage, as microorganisms can develop resistance and subsequently survive previously effective control procedures. To overcome these barriers, interdisciplinary research collaboration among academic and research institutions, industry, government, and other stakeholders would be essential. Future research addressing cost, economics, and safety is likely to overcome many of the current limitations and create more opportunities for biofilm control.

\section{Conflict of Interests}

The authors declare that there is no conflict of interests regarding the publication of this paper.

\section{Acknowledgments}

This study was financially supported by National Natural Science Foundation of China (No. 41373141, 21107099), One Hundred Talents Program of Chinese Academy of Sciences ([2014], No. 63), Foundation from Guangdong Science and Technology Department (2013B030800001), 1000 Talent Plan for High-Level Foreign Experts funded by China Bureau of Foreign Experts Affairs ([2014], No. 49), CAS Adjunct Professorship (No. 2013T1G0038, GJHS2014090100463583), and Shenzhen Science, Technology and Innovation Commission (Nos. 
888 JCYJ20140509174140691， JCYJ20140417113430641， JCYJ20140417113430732,

889 JSKF20150831171545604 and JSGG20150602143328010).

890 
891

892

893

894

895

896

897

898

899

900

901

902

903

904

905

906

907

908

909

910

911

912

\section{Reference}

Adams, L.K., Lyon, D.Y., and Alvarez, P.J. 2006. Comparative eco-toxicity of nanoscale $\mathrm{TiO}_{2}, \mathrm{SiO}_{2}$, and $\mathrm{ZnO}$ water suspensions. Water Res. 40(19): 3527-3532. doi: 10.1016/j.watres.2006.08.004.

Alekseeva, O.V., Bagrovskaya, N.A., Noskov, A.V. 2014. Effect of C 60 filling on structure and properties of composite films based on polystyrene. Arabian Journal of Chemistry. doi: 10.1016/j.arabjc.2014.09.008.

Ali, K., Ahmed, B., Dwivedi, S., Saquib, Q., Al-Khedhairy, A.A., Musarrat, J. 2015. Microwave accelerated green synthesis of stable silver nanoparticles with eucalyptus globulus leaf extract and their antibacterial and antibiofilm activity on clinical isolates. PloS one. 10(7): e131178. doi: 10.1371/journal.pone.0131178

Anghel, I., Grumezescu, A.M., Holban, A.M., Ficai, A., Anghel, A.G., Chifiriuc, M.C. 2013. Biohybrid nanostructured iron oxide nanoparticles and Satureja hortensis to prevent fungal biofilm development. Int. J. Mol. Sci. 14(9): 18110-18123. doi: 10.3390/ijms 140918110 .

Ansari, M.A., Khan, H.M., Khan, A.A., Cameotra, S.S., Saquib, Q., Musarrat, J. 2014. Gum arabic capped - silver nanoparticles inhibit biofilm formation by multi drug resistant strains of Pseudomonas aeruginosa. Journal of basic microbiology. 54(7): 688-699. doi: 10.1002/jobm.201300748.

Ansari, M.A., Khan, H.M., Khan, A.A., Cameotra, S.S., Alzohairy, M.A. 2015. Anti-biofilm efficacy of silver nanoparticles against MRSA and MRSE isolated from wounds in a tertiary care hospital. Indian journal of medical microbiology. 

33(1): 101-109. doi: 10.4103/0255-0857.148402.

914 Aoshima, H., Kokubo, K., Shirakawa, S., Ito, M., Yamana, S., Oshima, T. 2009. 915 Antimicrobial activity of fullerenes and their hydroxylated derivatives. 916 Biocontrol. Sci. 14(2): 69-72. doi: 10.4265/bio.14.69

917 Applerot, G., Lellouche, J., Perkas, N., Nitzan, Y., Gedanken, A., and Banin, E. 2012. $918 \mathrm{ZnO}$ nanoparticle-coated surfaces inhibit bacterial biofilm formation and increase 919 antibiotic susceptibility. RSC Adv. 2(6): 2314-2321. doi: 10.1039/C2RA00602B. 920 Arabatzis, I.M., Stergiopoulos, T., Bernard, M.C., Labou, D., Neophytides, S.G., and 921 Falaras, P. 2003. Silver-modified titanium dioxide thin films for efficient 922 photodegradation of methyl orange. Appl. Catal. B: Environ. 42(2): 187-201. doi: 10.1016/S0926-3373(02)00233-3.

924

Arias, L.R., and Yang, L. 2009. Inactivation of bacterial pathogens by carbon nanotubes in suspensions. Langmuir, 25(5): 3003-3012. doi: 10.1021/la802769m.

Aslan, S., Loebick, C.Z., Kang, S., Elimelech, M., Pfefferle, L.D., and Van Tassel, P.R. 2010. Antimicrobial biomaterials based on carbon nanotubes dispersed in poly (lactic-co-glycolic acid). Nanoscale, 2(9): 1789-1794. doi: 10.1039/c0nr00329h.

Auffan, M., Rose, J., Bottero, J., Lowry, G.V., Jolivet, J., Wiesner, M.R. 2009. Towards a definition of inorganic nanoparticles from an environmental, health and safety perspective. Nature nanotechnology. 4(10): 634-641. doi: 10.1038/nnano.2009.242.

Bakkiyaraj, D., Pandian, S.K. 2014. Biofilm inhibition by nanoparticles. Springer, pp: $385-406$. 
935

936

937

938

939

940

941

942

943

944

945

946

947

948

949

950

951

952

953

954

955

956

Ballatore, M.B., Durantini, J., Gsponer, N.S., Suarez, M.B., Gervaldo, M., Otero, L., Spesia, M.B., Milanesio, M.E., Durantini, E.N. 2015. Photodynamic inactivation of bacteria using novel electrogenerated porphyrin-fullerene C60 polymeric films. Environ. Sci. Technol. 49(12): 7456-7463. doi: 10.1021/acs.est.5b01407.

Benabbou, A.K., Derriche, Z., Felix, C., Lejeune, P., and Guillard, C. 2007. Photocatalytic inactivation of Escherischia coli: effect of concentration of $\mathrm{TiO}_{2}$ and microorganism, nature, and intensity of UV irradiation. Appl. Catal. B: Environ. 76(3): 257-263. doi: 10.1016/j.apcatb.2007.05.026.

Beyth, N., Houri-Haddad, Y., Domb, A., Khan, W., and Hazan, R. 2015. Alternative antimicrobial approach: nano-antimicrobial materials. Evid. Based. Complement. Alternat. Med. 2015: 246012. doi: 10.1155/2015/246012.

Bhadra, P., Mitra, M., Das, G., Dey, R., and Mukherjee, S. 2011. Interaction of chitosan capped $\mathrm{ZnO}$ nanorods with Escherichia coli. Mater. Sci. Eng. C, 31(5): 929-937. doi: 10.1016/j.msec.2011.02.015.

Blecher, K., Nasir, A., and Friedman, A. 2011. The growing role of nanotechnology in combating infectious disease. Virulence, 2(5): 395-401. doi: 10.4161/viru.2.5.17035.

Brady-Estévez, A.S., Kang, S., and Elimelech, M. 2008. A single - walled - carbon nanotube filter for removal of viral and bacterial pathogens. Small, 4(4): 481-484. doi: $10.1002 /$ smll.200700863.

Brady-Estévez, A.S., Nguyen, T.H., Gutierrez, L., and Elimelech, M. 2010. Impact of solution chemistry on viral removal by a single-walled carbon nanotube filter. 
957

958

959

960

961

962

963

964

965

966

967

968

969

970

971

972

973

974

975

976

977

978

Water Res. 44(13): 3773-3780. doi: 10.1016/j.watres.2010.04.023.

Brant, J.A., Labille, J., Bottero, J.Y., and Wiesner, M.R. 2006. Characterizing the impact of preparation method on fullerene cluster structure and chemistry. Langmuir, 22(8): 3878-3885. doi: 10.1021/la053293o.

Buzea, C., Pacheco, I.I., Robbie, K. 2007. Nanomaterials and nanoparticles: sources and toxicity. Biointerphases. 2(4): R17-R71. doi: 10.1116/1.2815690

Bystrzejewska-Piotrowska, G., Golimowski, J., Urban, P.L. 2009. Nanoparticles: their potential toxicity, waste and environmental management. Waste Management. 29(9): 2587-2595. doi: 10.1016/j.wasman.2009.04.001.

Carlson, R.P., Reed, T., Davison, W.M., Stewart, P.S. 2008. Anti-biofilm properties of chitosan-coated surfaces. Journal of Biomaterials Science Polymer Edition. 19(8): 1035-1046. doi: 10.1163/156856208784909372.

Castillo-Martínez, J.C., Martínez-Castañón, G.A., Martínez-Gutierrez, F., Zavala-Alonso, N.V., Patiño-Marín, N., Niño-Martinez, N., Zaragoza-Magaña, V., Cabral-Romero, C. 2015. Antibacterial and antibiofilm activities of the photothermal therapy using gold nanorods against seven different bacterial strains. Journal of Nanomaterials, 2015(7):1-7. doi: 10.1155/2015/783671

Cataldo, F., and Da Ros, T. 2008. Medicinal chemistry and pharmacological potential of fullerenes and carbon nanotubes. Springer Science \& Business Media.

Chen, M., Yu, Q., Sun, H. 2013. Novel strategies for the prevention and treatment of biofilm related infections. Int. J. Mol. Sci. 14(9): 18488-18501. doi: $10.3390 /$ ijms 140918488 
979 Choi, H., Stathatos, E., and Dionysiou, D.D. 2007a. Photocatalytic $\mathrm{TiO}_{2}$ films and 980 membranes for the development of efficient wastewater treatment and reuse 981 systems. Desalination, 202(1): 199-206. doi: 10.1016/j.desal.2005.12.055.

982 Choi, J.Y., Kim, K.H., Choy, K.C., Oh, K.T., and Kim, K.N. 2007b. Photocatalytic antibacterial effect of $\mathrm{TiO}_{2}$ film formed on $\mathrm{Ti}$ and $\mathrm{TiAg}$ exposed to Lactobacillus acidophilus. J. Biomed. Mater. Res. B Appl. Biomater. 80(2): 353-359. doi: 10.1002/jbm.b.30604.

Chung, Y.C., Wang, H.L., Chen, Y.M., and Li, S.L. 2003. Effect of abiotic factors on

Cloete, T.E. 2003. Resistance mechanisms of bacteria to antimicrobial compounds. Int. Biodeterior. Biodegrad. 51(4): 277-282. doi: 10.1016/S0964-8305(03)00042-8.

da Silva, B.F., Pérez, S., Gardinalli, P., Singhal, R.K., Mozeto, A.A., and Barceló, D. 2011. Analytical chemistry of metallic nanoparticles in natural environments. TrAC, Trends Anal. Chem. 30(3): 528-540. doi: 10.1016/j.trac.2011.01.008.

Dankovich, T.A., and Gray, D.G. 2011. Bactericidal paper impregnated with silver nanoparticles for point-of-use water treatment. Environ. Sci. Technol. 45(5): 1992-1998. doi: 10.1021/es103302t.

Darabpour, E., Kashef, N., Mashayekhan, S. 2016. Chitosan nanoparticles enhance the efficiency of methylene blue-mediated antimicrobial photodynamic inactivation of bacterial biofilms: An in vitro study. Photodiagnosis Photodyn. Ther. 14: 211-217. doi: 10.1016/j.pdpdt.2016.04.009 
1001

1002

1003

1004

1005

1006

1007

1008

1009

1010

1011

1012

1013

1014

1015

1016

1017

1018

1019

1020

1021

1022

Dastjerdi, R., and Montazer, M. 2010. A review on the application of inorganic nano-structured materials in the modification of textiles: focus on anti-microbial properties. Colloids Surf. B Biointerfaces. 79(1): 5-18. doi: 10.1016/j.colsurfb.2010.03.029.

Davey, M.E., and O'toole, G.A. 2000. Microbial biofilms: from ecology to molecular genetics. Microbiol. Mol. Biol. Rev. 64(4): 847-867. doi: 10.1128/MMBR.64.4.847-867.2000.

Davies, J., Davies, D. 2010. Origins and evolution of antibiotic resistance. Microbiol. Mol. Biol. Rev. 74(3): 417-433. doi: 10.1128/MMBR.00016-10

Dawson, T.L. 2008. Nanomaterials for textile processing and photonic applications. Color. Technol. 124(5): 261-272. doi: 10.1111/j.1478-4408.2008.00151.x.

Defoirdt, T., Brackman, G., and Coenye, T. 2013. Quorum sensing inhibitors: how strong is the evidence? Trends Microbiol. 21(12): 619-624. doi: 10.1016/j.tim.2013.09.006.

Deryabin, D.G., Davydova, O.K., Yankina, Z.Z., Vasilchenko, A.S., Miroshnikov, S.A., Kornev, A.B., Ivanchikhina, A.V., and Troshin, P.A. 2014. The activity of [60] fullerene derivatives bearing amine and carboxylic solubilizing groups against Escherichia coli: a comparative study. J. Nanomater. 2014: 2. doi: $10.1155 / 2014 / 907435$.

de Paz, L.E.C., Resin, A. Howard, K.A., Sutherland, D.S., Wejse, P.L. 2011. Antimicrobial effect of chitosan nanoparticles on Streptococcus mutans biofilms. Appl. Environ. Microbiol. 77(11): 3892-3895. doi: 10.1128/AEM.02941-10 
1023

1024

1025

1026

1027

1028

1029

1030

1031

1032

1033

1034

1035

1036

1037

1038

1039

1040

1041

1042

1043

1044

Desai, V.S., and Kowshik, M. 2009. Antimicrobial activity of titanium dioxide nanoparticles synthesized by sol-gel technique. Research Journal of Microbiology, 4(3): 97-103. doi: 10.3923/jm.2009.97.103.

de Souza, M.E., de Almeida Vaucher, R., Santos, R.C.V. 2014. Antibiofilm applications of nanotechnology. Fungal Genomics \& Biology. doi: $10.4172 / 2165-8056.1000 \mathrm{e} 117$

Dhillon, G.S., Kaur, S., Brar, S.K., 2014. Facile fabrication and characterization of chitosan-based zinc oxide nanoparticles and evaluation of their antimicrobial and antibiofilm activity. International Nano Letters. 4(2): 1-11. doi: $10.1007 / \mathrm{s} 40089-014-0107-6$

Dizaj, S.M., Mennati, A., Jafari, S., Khezri, K., Adibkia, K., 2015. Antimicrobial activity of carbon-based nanoparticles. Adv Pharm Bull. 5(1): 19. doi: 10.5681/apb.2015.003

Don, T.M., Chen, C.C., Lee, C.K., Cheng, W.Y., and Cheng, L.P. 2005. Preparation and antibacterial test of chitosan/PAA/PEGDA bi-layer composite membranes. J. Biomater. Sci. Polym. Ed. 16(12): 1503-1519. doi: $10.1163 / 156856205774576718$.

Dong, L., Henderson, A., and Field, C. 2012. Antimicrobial Activity of Single-Walled Carbon Nanotubes Suspended in Different Surfactants. Journal of Nanotechnology, 2012: 1-7. doi: 10.1155/2012/928924.

Dong, X., McCoy, E., Zhang, M., Yang, L. 2014. Inhibitory effects of nisin-coated multi-walled carbon nanotube sheet on biofilm formation from Bacillus anthracis 
spores. Journal of Environmental Sciences. 26(12): 2526-2534. doi: 10.1016/j.jes.2014.04.010

1047

1048

1049

1050

1051

1052

1053

1054

1055

1056

1057

1058

1059

1060

1061

1062

1063

1064

1065

1066

Dong, X., Yang, L. 2014. Inhibitory effects of single-walled carbon nanotubes on biofilm formation from Bacillus anthracis spores. Biofouling. 30(10): 1165-1174. doi: $10.1080 / 08927014.2014 .975797$

Dong, Y.H., Gusti, A.R., Zhang, Q., Xu, J.L., and Zhang, L.H. 2002. Identification of quorum-quenching N-acyl homoserine lactonases from Bacillus species. Appl. Environ. Microbiol. 68(4): 1754-1759. doi: 10.1128/AEM.68.4.1754-1759.2002.

Donlan, R.M. 2002. Biofilms: microbial life on surfaces. Emerg. Infect. Dis. 8(9): 881-890. doi: 10.3201/eid0809.020063.

Dos Santos, V.M., Yakimov, M.M., Timmis, K.N., Golyshin, P.N. 2008. Genomic insights into oil biodegradation in marine systems. Microbial biodegradation: genomic and molecular biology.

Drake, P.L., and Hazelwood, K.J. 2005. Exposure-related health effects of silver and silver compounds: a review. Ann. Occup. Hyg. 49(7): 575-585. doi: 10.1093/annhyg/mei019.

Dutta, R.K., Sharma, P.K., Bhargava, R., Kumar, N., and Pandey, A.C. 2010. Differential susceptibility of Escherichia coli cells toward transition metal-doped and matrix-embedded ZnO nanoparticles. J. Phys. Chem. B, 114(16): 5594-5599. doi: $10.1021 / \mathrm{jp} 1004488$.

Duncan, L.K., Jinschek, J.R., Vikesland, P.J. 2007. C60 colloid formation in aqueous systems: effects of preparation method on size, structure, and surface charge. 
1067

1068

1069

1070

1071

1072

1073

1074

1075

1076

1077

1078

1079

1080

1081

1082

1083

1084

1085

1086

1087

1088

Environ. Sci. Technol. 42(1): 173-178. doi: 10.1021/es071248s

Dwivedi, S., Wahab, R., Khan, F., Mishra, Y.K., Musarrat, J., Al-Khedhairy, A.A. 2014. Reactive oxygen species mediated bacterial biofilm inhibition via zinc oxide nanoparticles and their statistical determination. PLoS One. 9(11): e111289. doi: 10.1371/journal.pone.0111289

Eckelman, M.J., Mauter, M.S., Isaacs, J.A., and Elimelech, M. 2012. New perspectives on nanomaterial aquatic ecotoxicity: production impacts exceed direct exposure impacts for carbon nanotoubes. Environ. Sci. Technol. 46(5): 2902-2910. doi: 10.1021/es203409a.

Eshed, M., Lellouche, J., Banin, E., Gedanken, A. 2013. MgF 2 nanoparticle-coated teeth inhibit Streptococcus mutans biofilm formation on a tooth model. J. Mater. Chem. B. 1(32): 3985-3991. doi: 10.1039/C3TB20598C

Eshed, M., Lellouche, J., Matalon, S., Gedanken, A. Banin, E. 2012. Sonochemical coatings of $\mathrm{ZnO}$ and $\mathrm{CuO}$ nanoparticles inhibit Streptococcus mutans biofilm formation on teeth model. Langmuir. 28(33): 12288-12295. doi: $10.1021 / 1 \mathrm{a} 301432 \mathrm{a}$

Espitia, P.J.P., Soares, N.d.F.F., Coimbra, J.S.d.R., de Andrade, N.J., Cruz, R.S., and Medeiros, E.A.A. 2012. Zinc Oxide Nanoparticles: Synthesis, Antimicrobial Activity and Food Packaging Applications. Food Bioprocess Tech. 5(5): 1447-1464. doi: 10.1007/s11947-012-0797-6.

Fabrega, J., Zhang, R., Renshaw, J.C., Liu, W., Lead, J.R. 2011. Impact of silver nanoparticles on natural marine biofilm bacteria. Chemosphere. 85(6): 961-966. 
1089

1090

1091

1092

1093

1094

1095

1096

1097

1098

1099

1100

1101

1102

1103

1104

1105

1106

1107

1108

1109

1110

doi: 10.1016/j.chemosphere.2011.06.066

Fang, J., Lyon, D.Y., Wiesner, M.R., Dong, J., and Alvarez, P.J. 2007. Effect of a fullerene water suspension on bacterial phospholipids and membrane phase behavior. Environ. Sci. Technol. 41(7): 2636-2642. doi: 10.1021/es062181w.

Fernandes, J.C., Tavaria, F.K., Fonseca, S.C., Ramos, Ó.S., Pintado, M.E., and Malcata, F.X. 2010. In vitro screening for anti-microbial activity of chitosans and chitooligosaccharides, aiming at potential uses in functional textiles. J. Microbiol. Biotechnol. 20(2): 311-318. doi: 10.4014/jmb.0904.04038.

Fernandes, J.C., Tavaria, F.K., Soares, J.C., Ramos, Ó.S., Monteiro, M.J., Pintado, M.E., and Malcata, F.X. 2008. Antimicrobial effects of chitosans and chitooligosaccharides, upon Staphylococcus aureus and Escherichia coli, in food model systems. Food Microbiol. 25(7): 922-928. doi: 10.1016/j.fm.2008.05.003.

Ferreira, C., Pereira, A., Melo, L., and Simoes, M. 2010. Advances in industrial biofilm control with micro-nanotechnology. Current Research, Technology and Education. Applied Microbiology and Microbial Biotechnology: 845-854. Available from http://www.formatex.info/microbiology2/845-854.pdf.

Fisher, J.F., Meroueh, S.O., Mobashery, S. 2005. Bacterial resistance to $\beta$-lactam antibiotics: compelling opportunism, compelling opportunity. Chem. Rev.105( 2): 395-424. doi: 10.1021/cr030102i

Flemming, H., Ridgway, H. 2008. Biofilm control: conventional and alternative approaches. doi: 10.1007/7142_2008_20

Flemming, H., Wingender, J. 2010. The biofilm matrix. Nature Reviews Microbiology. 
1111

1112

1113

1114

1115

1116

1117

1118

1119

1120

1121

1122

1123

1124

1125

1126

1127

1128

1129

1130

1131

1132

8(9): 623-633. doi: 10.1038/nrmicro2415

Fortner, J.D., Lyon, D.Y., Sayes, C.M., Boyd, A.M., Falkner, J.C., Hotze, E.M., Alemany, L.B., Tao, Y.J., Guo, W., Ausman, K.D., Colvin, V.L., and Hughes, J.B. 2005. C60 in water: nanocrystal formation and microbial response. Environ. Sci. Technol. 39(11): 4307-4316. doi: 10.1021/es048099n.

Frank, S.N., and Bard, A.J. 1977. Heterogeneous photocatalytic oxidation of cyanide and sulfite in aqueous solutions at semiconductor powders. J. Phys. Chem. 81(15): 1484-1488. doi: 10.1021/j100530a011.

Friedman, A.J., Phan, J., Schairer, D.O., Champer, J., Qin, M., Pirouz, A., Blecher-Paz, K., Oren, A., Liu, P.T., Modlin, R.L., and Kim, J. 2013. Antimicrobial and anti-inflammatory activity of chitosan-alginate nanoparticles: a targeted therapy for cutaneous pathogens. J. Invest. Dermatol. 133(5): 1231-1239. doi: 10.1038/jid.2012.399.

Gao, L., Giglio, K.M., Nelson, J.L., Sondermann, H., Travis, A.J. 2014. Ferromagnetic nanoparticles with peroxidase-like activity enhance the cleavage of biological macromolecules for biofilm elimination. Nanoscale. 6(5): 2588-2593. doi: 10.1039/C3NR05422E

Garcia-Lara, B., Saucedo-Mora, M.A., Roldan-Sanchez, J.A., Perez-Eretza, B., Ramasamy, M., Lee, J., Coria-Jimenez, R., Tapia, M., Varela-Guerrero, V., Garcia-Contreras, R., 2015. Inhibition of quorum-sensing-dependent virulence factors and biofilm formation of clinical and environmental Pseudomonas aeruginosa strains by ZnO nanoparticles. Lett. Appl. Microbiol. 61(3): 299-305. 
doi: 10.1111/lam.12456.

Geppert, M., Hohnholt, M., Gaetjen, L., Grunwald, I., Bäumer, M., and Dringen, R. 2009. Accumulation of iron oxide nanoparticles by cultured brain astrocytes. J. Biomed. Nanotechnol. 5(3): 285-293. doi: 10.1166/jbn.2009.1033.

Gholap, H., Warule, S., Sangshetti, J., Kulkarni, G., Banpurkar, A., Satpute, S., Patil, R. 2016. Hierarchical nanostructures of $\mathrm{Au@} \mathrm{ZnO:} \mathrm{antibacterial} \mathrm{and} \mathrm{antibiofilm}$ agent. Appl. Microbiol. Biotechnol. 1-10. doi: 10.1007/s00253-016-7391-1

Ghosh, S., Kaushik, R., Nagalakshmi, K., Hoti, S., Menezes, G., Harish, B., and Vasan, H. 2010. Antimicrobial activity of highly stable silver nanoparticles embedded in agar-agar matrix as a thin film. Carbohydr. Res. 345(15): 2220-2227. doi: 10.1016/j.carres.2010.08.001.

Gogniat, G., and Dukan, S. 2007. $\mathrm{TiO}_{2}$ photocatalysis causes DNA damage via fenton reaction-generated hydroxyl radicals during the recovery period. Appl. Environ. Microbiol. 73(23): 7740-7743. doi: 10.1128/AEM.01079-07.

Goodwin Jr, D.G., Marsh, K.M., Sosa, I.B., Payne, J.B., Gorham, J.M., Bouwer, E.J., Fairbrother, D.H. 2015. Interactions of microorganisms with polymer nanocomposite surfaces containing oxidized carbon nanotubes. Environ. Sci. Technol. 49(9): 5484-5492. doi: 10.1021/acs.est.5b00084

Gordon, O., Vig Slenters, T., Brunetto, P.S., Villaruz, A.E., Sturdevant, D.E., Otto, M., Landmann, R., and Fromm, K.M. 2010. Silver coordination polymers for prevention of implant infection: thiol interaction, impact on respiratory chain enzymes, and hydroxyl radical induction. Antimicrob. Agents Chemother. 54(10): 
4208-4218. doi: 10.1128/AAC.01830-09.

Gordon, T., Perlstein, B., Houbara, O., Felner, I., Banin, E., and Margel, S. 2011. Synthesis and characterization of zinc/iron oxide composite nanoparticles and their antibacterial properties. Colloid Surf. A: Physicochem. Eng. Asp. 374(1): 1-8. doi: 10.1016/j.colsurfa.2010.10.015.

Goswami, S.R., Sahareen, T., Singh, M., Kumar, S. 2015. Role of biogenic silver nanoparticles in disruption of cell-cell adhesion in Staphylococcus aureus and Escherichia coli biofilm. Journal of Industrial and Engineering Chemistry, 26: 73-80. doi: 10.1016/j.jiec.2014.11.017

Gurunathan, S., Han, J.W., Kwon, D., Kim, J. 2014. Enhanced antibacterial and anti-biofilm activities of silver nanoparticles against Gram-negative and Gram-positive bacteria. Nanoscale research letters. 9(1): 373. doi: $10.1186 / 1556-276 X-9-373$

Habash, M.B., Park, A.J., Vis, E.C., Harris, R.J., Khursigara, C.M. 2014. Synergy of silver nanoparticles and aztreonam against Pseudomonas aeruginosa PAO1 biofilms. Antimicrob. Agents Chemother. 58(10): 5818-5830. doi: 10.1128/AAC.03170-14

Haghighi, F., Roudbar Mohammadi, S., Mohammadi, P., Hosseinkhani, S., Shipour, R. 2013. Antifungal Activity of $\mathrm{TiO} 2$ nanoparticles and EDTA on Candida albicans Biofilms. Infect. $\quad$ Epidemiol. $\quad$ Med. 1(1): 33-38. $\underline{\text { http://iem.modares.ac.ir/article_10035 3ce8159da985eb44ab5cf379f622efb2.pdf }}$ Hall-Stoodley, L., Costerton, J.W., and Stoodley, P. 2004. Bacterial biofilms: from the 
1177

1178

1179

1180

1181

1182

1183

1184

1185

1186

1187

1188

1189

1190

1191

1192

1193

1194

1195

1196

1197

1198

natural environment to infectious diseases. Nat. Rev. Microbiol. 2(2): 95-108. doi: $10.1038 /$ nrmicro821.

Hassani Sangani, M., Nakhaei Moghaddam, M., Forghanifard, M.M. 2015. Inhibitory effect of zinc oxide nanoparticles on pseudomonas aeruginosa biofilm formation. Nanomedicine Journal. 4(2): 121-128. doi: 10.7508/nmj.2015.02.004

He, L., Liu, Y., Mustapha, A., Lin, M. 2011. Antifungal activity of zinc oxide nanoparticles against Botrytis cinerea and Penicillium expansum. Microbiological research. 166(3): 207-215. doi: 10.1016/j.micres.2010.03.003

Hindi, K.M., Ditto, A.J., Panzner, M.J., Medvetz, D.A., Han, D.S., Hovis, C.E., Hilliard, J.K., Taylor, J.B., Yun, Y.H., and Cannon, C.L. 2009. The antimicrobial efficacy of sustained release silver-carbene complex-loaded L-tyrosine polyphosphate nanoparticles: Characterization, in vitro and in vivo studies. Biomaterials, 30(22): 3771-3779. doi: 10.1016/j.biomaterials.2009.03.044.

Hossain, F., Perales-Perez, O.J., Hwang, S., and Roman, F. 2014. Antimicrobial nanomaterials as water disinfectant: applications, limitations and future $\begin{array}{llllll}\text { perspectives. Sci. Total Environ. 466-467: 1047-1059. doi: } & \end{array}$ 10.1016/j.scitotenv.2013.08.009.

Huang, Z., Maness, P.-C., Blake, D.M., Wolfrum, E.J., Smolinski, S.L., and Jacoby, W.A. 2000. Bactericidal mode of titanium dioxide photocatalysis. J. Photochem. Photobiol. A Chem. 130(2): 163-170. doi: 10.1016/S1010-6030(99)00205-1.

Huh, A.J., and Kwon, Y.J. 2011. "Nanoantibiotics": a new paradigm for treating infectious diseases using nanomaterials in the antibiotics resistant era. J. Control. 
1199

1200

1201

1202

1203

1204

1205

1206

1207

1208

1209

1210

1211

1212

1213

1214

1215

1216

1217

1218

1219

1220

Release. 156(2): 128-145. doi: 10.1016/j.jconrel.2011.07.002.

Hyung, H., Fortner, J.D., Hughes, J.B., and Kim, J.-H. 2007. Natural organic matter stabilizes carbon nanotubes in the aqueous phase. Environ. Sci. Technol. 41(1): 179-184. doi: 10.1021/es061817g.

Ibrahim, M., Tao, Z., Hussain, A., Chunlan, Y., Ilyas, M., Waheed, A., Yuan, F., Li, B., and Xie, G.L. 2014. Deciphering the role of Burkholderia cenocepacia membrane proteins in antimicrobial properties of chitosan. Arch. Microbiol. 196(1): 9-16. doi: 10.1007/s00203-013-0936-0.

Inbakandan, D., Kumar, C., Abraham, L.S., Kirubagaran, R., Venkatesan, R., and Khan, S.A. 2013. Silver nanoparticles with anti microfouling effect: a study against marine biofilm forming bacteria. Colloids Surf. B Biointerfaces, 111: 636-643. doi: 10.1016/j.colsurfb.2013.06.048.

Ip, M., Lui, S.L., Poon, V.K., Lung, I., and Burd, A. 2006. Antimicrobial activities of silver dressings: an in vitro comparison. J. Med. Microbiol. 55(Pt 1): 59-63. doi: 10.1099/jmm.0.46124-0.

Jalal, R., Goharshadi, E.K., Abareshi, M., Moosavi, M., Yousefi, A., and Nancarrow, P. 2010. ZnO nanofluids: green synthesis, characterization, and antibacterial activity. Mater. Chem. Phys. 121(1): 198-201. doi: 10.1016/j.matchemphys.2010.01.020.

Jamil, B., Habib, H., Abbasi, S.A., Ihsan, A., Nasir, H., Imran, M. 2016. Development of Cefotaxime Impregnated Chitosan as Nano-antibiotics: De Novo Strategy to Combat Biofilm Forming Multi-drug Resistant Pathogens. Front Microbiol. 7: 330. doi: $10.3389 /$ fmicb. 2016.00330 
1221

1222

1223

1224

1225

1226

1227

1228

1229

1230

1231

1232

1233

1234

1235

1236

1237

1238

1239

1240

1241

1242

Je, J.-Y., and Kim, S.-K. 2006. Chitosan derivatives killed bacteria by disrupting the outer and inner membrane. J. Agric. Food. Chem. 54(18): 6629-6633. doi: 10.1021/jf061310p.

Jena, P., Mohanty, S., Mallick, R., Jacob, B., and Sonawane, A. 2012. Toxicity and antibacterial assessment of chitosancoated silver nanoparticles on human pathogens and macrophage cells. Int. J. Nanomedicine. 7: 1805. doi: 10.2147/IJN.S28077.

Jin, T., Sun, D., Su, J., Zhang, H., and Sue, H.J. 2009. Antimicrobial efficacy of zinc oxide quantum dots against Listeria monocytogenes, Salmonella enteritidis, and Escherichia coli O157: H7. J. Food Sci. 74(1): M46-M52. doi: 10.1111/j.1750-3841.2008.01013.x.

Jones, N., Ray, B., Ranjit, K.T., and Manna, A.C. 2008. Antibacterial activity of ZnO nanoparticle suspensions on a broad spectrum of microorganisms. FEMS Microbiol. Lett. 279(1): 71-76. doi: 10.1111/j.1574-6968.2007.01012.x.

Kalishwaralal, K., BarathManiKanth, S., Pandian, S.R.K., Deepak, V., Gurunathan, S. 2010. Silver nanoparticles impede the biofilm formation by Pseudomonas aeruginosa and Staphylococcus epidermidis. Colloids and Surfaces B: Biointerfaces. 79(2): 340-344. doi: 10.1016/j.colsurfb.2010.04.014

Kang, S., Herzberg, M., Rodrigues, D.F., and Elimelech, M. 2008. Antibacterial effects of carbon nanotubes: size does matter! Langmuir, 24(13): 6409-6413. doi: 10.1021/la800951v.

Kang, S., Pinault, M., Pfefferle, L.D., and Elimelech, M. 2007. Single-walled carbon 
1243

1244

1245

1246

1247

1248

1249

1250

1251

1252

1253

1254

1255

1256

1257

1258

1259

1260

1261

1262

1263

1264

nanotubes exhibit strong antimicrobial activity. Langmuir, 23(17): 8670-8673. doi: $10.1021 / 1 \mathrm{la} 701067 \mathrm{r}$.

Kasraei, S., Sami, L., Hendi, S., AliKhani, M.-Y., Rezaei-Soufi, L., and Khamverdi, Z. 2014. Antibacterial properties of composite resins incorporating silver and zinc oxide nanoparticles on Streptococcus mutans and Lactobacillus. Restor. Dent. Endod. 39(2): 109-114. doi: 10.5395/rde.2014.39.2.109.

Khan, S.N., Khan, A.U., 2016. Breaking the Spell: Combating Multidrug Resistant ‘Superbugs’. Front Microbiol. 7: 174. doi: 10.3389/fmicb.2016.00174

Khan, S.T., Ahmad, J., Ahamed, M., Musarrat, J., Al-Khedhairy, A.A. 2016. Zinc oxide and titanium dioxide nanoparticles induce oxidative stress, inhibit growth, and attenuate biofilm formation activity of Streptococcus mitis. J Biol Inorg Chem. 21(3): 295-303. doi: 10.1007/s00775-016-1339-x

Khiralla, G.M., El-Deeb, B.A. 2015. Antimicrobial and antibiofilm effects of selenium nanoparticles on some foodborne pathogens. LWT-Food Science and Technology. 63(2): 1001-1007. doi: 10.1016/j.lwt.2015.03.086

Knetsch, M.L.W., and Koole, L.H. 2011. New Strategies in the Development of Antimicrobial Coatings: The Example of Increasing Usage of Silver and Silver Nanoparticles. Polymers, 3(4): 340-366. doi: 10.3390/polym3010340.

Kühn, K.P., Chaberny, I.F., Massholder, K., Stickler, M., Benz, V.W., Sonntag, H.-G., and Erdinger, L. 2003. Disinfection of surfaces by photocatalytic oxidation with titanium dioxide and UVA light. Chemosphere, 53(1): 71-77. doi: 10.1016/S0045-6535(03)00362-X. 
1265 Kulshrestha, S., Khan, S., Hasan, S., Khan, M.E., Misba, L., Khan, A.U. 2016.

1266 Calcium fluoride nanoparticles induced suppression of Streptococcus mutans

1267 biofilm: an in vitro and in vivo approach. Appl Microbiol Biotechnol. 100(4),

1268 1901-1914. doi: 10.1007/s00253-015-7154-4

1269 Kumar, C.G., Sujitha, P. 2014. Green synthesis of Kocuran-functionalized silver

1270 glyconanoparticles for use as antibiofilm coatings on silicone urethral catheters.

1271 Nanotechnology. 25(32): 325101. doi: 10.1088/0957-4484/25/32/325101.

1272 Lara, H.H., Ayala-Núñez, N.V., Ixtepan Turrent, L.d.C., and Rodríguez Padilla, C.

1273 2010. Bactericidal effect of silver nanoparticles against multidrug-resistant

1274 bacteria. World J. Microbiol. Biotechnol. 26(4): 615-621. doi:

$1275 \quad 10.1007 / \mathrm{s} 11274-009-0211-3$.

1276 Lara, H.H., Romero-Urbina, D.G., Pierce, C., Lopez-Ribot, J.L., Arellano-Jiménez,

1277 M.J., Jose-Yacaman, M. 2015. Effect of silver nanoparticles on Candida albicans

1278 biofilms: an ultrastructural study. Journal of nanobiotechnology. 13(1): 1. doi:

$1279 \quad 10.1186 / \mathrm{s} 12951-015-0147-8$

1280 Leaper, D.J. 2006. Silver dressings: their role in wound management. Int. Wound J.

$1281 \quad 3(4): 282-294$. doi: 10.1111/j.1742-481X.2006.00265.x.

1282 Lee, H.J., and Jeong, S.H. 2005. Bacteriostasis and skin innoxiousness of nanosize

1283 silver colloids on textile fabrics. Text. Res. J. 75(7): 551-556. doi:

$1284 \quad 10.1177 / 0040517505053952$.

1285 Lee, J.H., Kim, Y.G., Cho, M.H., Lee, J. 2014. ZnO nanoparticles inhibit

1286 Pseudomonas aeruginosa biofilm formation and virulence factor production. 
1287

1288

1289

1290

1291

1292

1293

1294

1295

1296

1297

1298

1299

1300

1301

1302

1303

1304

1305

1306

1307

1308

Microbiological research, 169(12): 888-896. doi: 10.1016/j.micres.2014.05.005.

Lee, J., Mackeyev, Y., Cho, M., Wilson, L.J., Kim, J.-H., and Alvarez, P.J. 2010. C60

aminofullerene immobilized on silica as a visible-light-activated photocatalyst.

Environ. Sci. Technol. 44(24): 9488-9495. doi: 10.1021/es1028475.

Leid, J.G., Ditto, A.J., Knapp, A., Shah, P.N., Wright, B.D., Blust, R., Christensen, L., Clemons, C.B., Wilber, J.P., Young, G.W., Kang, A.G., Panzner, M.J., Cannon, C.L., Yun, Y.H., Youngs, W.J., Seckinger, N.M., and Cope, E.K. 2012. In vitro antimicrobial studies of silver carbene complexes: activity of free and nanoparticle carbene formulations against clinical isolates of pathogenic bacteria. J. Antimicrob. Chemother. 67(1): 138-148. doi: 10.1093/jac/dkr408.

Lellouche, J., Kahana, E., Elias, S., Gedanken, A., Banin, E. 2009. Antibiofilm activity of nanosized magnesium fluoride. Biomaterials. 30(30): 5969-5978. doi: 10.1016/j.biomaterials.2009.07.037

Levard, C., Hotze, E.M., Lowry, G.V., Brown Jr, G.E., 2012. Environmental transformations of silver nanoparticles: impact on stability and toxicity. Environ. Sci. Technol. 46(13): 6900-6914. doi: 10.1021/es2037405

Li, D., Lyon, D.Y., Li, Q., and Alvarez, P.J. 2008a. Effect of soil sorption and aquatic natural organic matter on the antibacterial activity of a fullerene water suspension. Environ. Toxicol. Chem. 27(9): 1888-1894. doi: 10.1897/07-548.1.

Li, Q., Mahendra, S., Lyon, D.Y., Brunet, L., Liga, M.V., Li, D., and Alvarez, P.J. 2008b. Antimicrobial nanomaterials for water disinfection and microbial control: potential applications and implications. Water Res. 42(18): 4591-4602. doi: 

10.1016/j.watres.2008.08.015.

Li, Y., Leung, P., Yao, L., Song, Q., and Newton, E. 2006. Antimicrobial effect of surgical masks coated with nanoparticles. J. Hosp. Infect. 62(1): 58-63. doi: 10.1016/j.jhin.2005.04.015.

Liu, S., Wei, L., Hao, L., Fang, N., Chang, M.W., Xu, R., Yang, Y., and Chen, Y. 2009a. Sharper and faster "nano darts" kill more bacteria: a study of antibacterial activity of individually dispersed pristine single-walled carbon nanotube. ACS nano, 3(12): 3891-3902. doi: 10.1021/nn901252r.

Liu, Y., He, L., Mustapha, A., Li, H., Hu, Z., and Lin, M. 2009b. Antibacterial activities of zinc oxide nanoparticles against Escherichia coli O157: H7. J. Appl. Microbiol. 107(4): 1193-1201. doi: 10.1111/j.1365-2672.2009.04303.x.

Lungu, M., Gavriliu, Ş., Enescu, E., Ion, I., Brătulescu, A., Mihăescu, G., Măruţescu, L., Chifiriuc, M.C. 2014. Silver-titanium dioxide nanocomposites as effective antimicrobial and antibiofilm agents. J Nanopart Res. 16(1): 1-15. doi: $10.1007 / \mathrm{s} 11051-013-2203-3$

Lyon, D.Y., Adams, L.K., Falkner, J.C., Alvarez, P.J. 2006. Antibacterial activity of fullerene water suspensions: effects of preparation method and particle size. Environ. Sci. Technol. 40(14): 4360-4366. doi: 10.1021/es0603655.

Lyon, D., Brown, D., and Alvarez, P. 2008a. Implications and potential applications of bactericidal fullerene water suspensions: effect of $\mathrm{nC}_{60}$ concentration, exposure conditions and shelf life. Water Sci. Technol. 57(10): 1533-1538. doi: 10.2166/wst.2008.282. 
1331

1332

1333

1334

1335

1336

1337

1338

1339

1340

1341

1342

1343

1344

1345

1346

1347

1348

1349

1350

1351

1352

Lyon, D.Y., Brown, D., Sundstrom, E.R., and Alvarez, P.J. 2008b. Assessing the antibiofouling potential of a fullerene-coated surface. Int. Biodeter. Biodegr. 62(4): 475-478. doi: 10.1016/j.ibiod.2007.11.007.

Lyon, D.Y., Brunet, L., Hinkal, G.W., Wiesner, M.R., and Alvarez, P.J. 2008c. Antibacterial activity of fullerene water suspensions $\left(\mathrm{nC}_{60}\right)$ is not due to ROS-mediated damage. Nano lett. 8(5): 1539-1543. doi: 10.1021/n10726398.

Lyon, D.Y., Fortner, J.D., Sayes, C.M., Colvin, V.L., Hughes, J.B. 2005. Bacterial cell association and antimicrobial activity of a C60 water suspension. Environmental Toxicology and Chemistry. 24(11): 2757-2762. doi: 10.1897/04-649R.1

Maleki Dizaj, S., Mennati, A., Jafari, S., Khezri, K., and Adibkia, K. 2015. Antimicrobial activity of carbon-based nanoparticles. Adv. Pharm. Bull. 5(1): 19-23. doi: 10.5681/apb.2015.003.

Maness, P.-C., Smolinski, S., Blake, D.M., Huang, Z., Wolfrum, E.J., and Jacoby, W.A. 1999. Bactericidal activity of photocatalytic $\mathrm{TiO}_{2}$ reaction: toward an understanding of its killing mechanism. Appl. Environ. Microbiol. 65(9): 4094-4098. Available from http://aem.asm.org/content/65/9/4094.full.pdf+html [accessed 29 June 1999].

Markovic, Z., Todorovic-Markovic, B., Kleut, D., Nikolic, N., Vranjes-Djuric, S., Misirkic, M., Vucicevic, L., Janjetovic, K., Isakovic, A., and Harhaji, L. 2007. The mechanism of cell-damaging reactive oxygen generation by colloidal fullerenes. $\quad$ Biomaterials, 28(36): 5437-5448. doi: 10.1016/j.biomaterials.2007.09.002. 
1353

1354

1355

1356

1357

1358

1359

1360

1361

1362

1363

1364

1365

1366

1367

1368

1369

1370

1371

1372

1373

1374

Markowska, K., Grudniak, A.M., and Wolska, K.I. 2013. Silver nanoparticles as an alternative strategy against bacterial biofilms. Acta Biochim. Pol. 60(4): 523-530.

Markowska-Szczupak, A., Ulfig, K., and Morawski, A.W. 2011. The application of titanium dioxide for deactivation of bioparticulates: An overview. Catal. Today, 169(1): 249-257. doi: 10.1016/j.cattod.2010.11.055.

Martinez-Gutierrez, F., Olive, P.L., Banuelos, A., Orrantia, E., Nino, N., Sanchez, E.M., Ruiz, F., Bach, H., and Av-Gay, Y. 2010. Synthesis, characterization, and evaluation of antimicrobial and cytotoxic effect of silver and titanium nanoparticles. Nanomedicine, 6(5): 681-688. doi: 10.1016/j.nano.2010.02.001.

Martinez-Gutierrez, F., Boegli, L., Agostinho, A., Sánchez, E.M., Bach, H., Ruiz, F., James, G. 2013. Anti-biofilm activity of silver nanoparticles against different microorganisms.

Biofouling

29(6):

651-660.

doi: $10.1080 / 08927014.2013 .794225$.

Mizuno, K., Zhiyentayev, T., Huang, L., Khalil, S., Nasim, F., Tegos, G.P., Gali, H., Jahnke, A., Wharton, T., and Hamblin, M.R. 2011. Antimicrobial photodynamic therapy with functionalized fullerenes: quantitative structure-activity relationships. J. Nanomed. Nanotechnol. 2(2): 1. doi: 10.4172/2157-7439.1000109.

Mohanty, S., Mishra, S., Jena, P., Jacob, B., Sarkar, B., Sonawane, A. 2012. An investigation on the antibacterial, cytotoxic, and antibiofilm efficacy of starch-stabilized silver nanoparticles. Nanomedicine: Nanotechnology, Biology and Medicine. 8(6): 916-924. doi: 10.1016/j.nano.2011.11.007 
1375 Monteiro, D.R., Gor:p, L.F., Silva, S., Negri, M., de Camargo, E.R., Oliveira, R., 1376 Barbosa, D.D.B., Henriques, M. 2011. Silver colloidal nanoparticles: antifungal 1377 effect against adhered cells and biofilms of Candida albicans and Candida 1378 glabrata. Biofouling. 27(7): 711-719. doi: 10.1080/08927014.2011.599101.

1379 Monteiro, D.R., Silva, S., Negri, M., Gorup, L.F., De Camargo, E.R., Oliveira, R., 1380 Barbosa, D.D.B., Henriques, M. 2012. Silver nanoparticles: influence of stabilizing agent and diameter on antifungal activity against Candida albicans and Candida glabrata biofilms. Letters in applied microbiology. 54(5): 383-391. doi: 10.1111/j.1472-765X.2012.03219.X

1384

1385

1386

Morsi, R.E., Labena, A., Khamis, E.A. 2016. Core/shell (ZnO/polyacrylamide) nanocomposite: In-situ emulsion polymerization, corrosion inhibition, anti-microbial and anti-biofilm characteristics. Journal of the Taiwan Institute of Chemical Engineers, 63: 512-522. doi: 10.1016/j.jtice.2016.03.037

Muranyi, P., Schraml, C., and Wunderlich, J. 2010. Antimicrobial efficiency of titanium dioxide - coated surfaces. J. Appl. Microbiol. 108(6): 1966-1973. doi: 10.1111/j.1365-2672.2009.04594.x.

Naik, K., Kowshik, M. 2014. Anti - quorum sensing activity of $\mathrm{AgCl}-\mathrm{TiO} 2$ nanoparticles with potential use as active food packaging material. Journal of applied microbiology. 117(4): 972-983. doi: 10.1111/jam.12589

Nakamura, S., and Mashino, T. 2009. Biological activities of water-soluble fullerene derivatives. J. Phys.: Conf. Ser. 159: 012003. doi: 10.1088/1742-6596/159/1/012003. 
1397

1398

Natarajan, K. 2015. Antibiofilm Activity of Epoxy/Ag-TiO2 Polymer Nanocomposite Coatings against Staphylococcus Aureus and Escherichia Coli. Coatings. 5(2): 95-114. doi: 10.3390/coatings5020095

Nicolella, C., Van Loosdrecht, M., Heijnen, J.J. 2000. Wastewater treatment with particulate biofilm reactors. Journal of biotechnology. 80(1): 1-33. doi: $10.1016 / \mathrm{S} 0168-1656(00) 00229-7$

Nithya, B., Jayachitra, A., 2016. Improved Antibacterial and Antibiofilm Activity of Plant Mediated Gold Nanoparticles using Garcinia cambogia. Int. J. Pure App. Biosci. 4(2): 201-210. http://www.ijpab.com/form/2016\%20Volume\%204,\%20issue $\% 202 / I J P A B-2016-$ 4-2-201-210.pdf

No, H.K., Park, N.Y., Lee, S.H., and Meyers, S.P. 2002. Antibacterial activity of chitosans and chitosan oligomers with different molecular weights. Int. J. Food Microbiol. 74(1): 65-72. doi: 10.1016/S0168-1605(01)00717-6.

Obraztsova, E., Lukashev, E., Zarubina, A., Parkhomenko, I., and Yaminsky, I. 2009. Bactericidal action of single-walled carbon nanotubes. Moscow University Physics Bulletin, 64(3): 320-323. doi: 10.3103/S0027134909030199.

Ohira, T., Yamamoto, O., Iida, Y., and Nakagawa, Z.-e. 2008. Antibacterial activity of ZnO powder with crystallographic orientation. J. Mater. Sci. Mater. Med. 19(3): 1407-1412. doi: 10.1007/s10856-007-3246-8.

Oppezzo, O.J., and Pizarro, R.A. 2001. Sublethal effects of ultraviolet A radiation on Enterobacter cloacae. J. Photochem. Photobiol. B: Biology,. 62(3): 158-165. doi: 
1419

1420

1421

1422

1423

1424

1425

1426

1427

1428

1429

1430

1431

1432

1433

1434

1435

1436

1437

1438

1439

1440

10.1016/S1011-1344(01)00180-4.

Padmavathy, N., and Vijayaraghavan, R. 2016. Enhanced bioactivity of ZnO nanoparticles_-an antimicrobial study. Sci. Technol. Adv. Mat. 9(3): 035004. doi: 10.1088/1468-6996/9/3/035004.

Pal, S., Tak, Y.K., and Song, J.M. 2007. Does the antibacterial activity of silver nanoparticles depend on the shape of the nanoparticle? A study of the gram-negative bacterium Escherichia coli. Appl. Environ. Microbiol. 73(6): 1712-1720. doi: 10.1128/AEM.02218-06.

Palanikumar, L., Ramasamy, S.N., and Balachandran, C. 2014. Size-dependent antimicrobial response of zinc oxide nanoparticles. IET Nanobiotechnol. 8(2): 111-117. doi: 10.1049/iet-nbt.2012.0008.

Palanisamy, N.K., Ferina, N., Amirulhusni, A.N., Mohd-Zain, Z., Hussaini, J., Ping, L.J., Durairaj, R. 2014. Antibiofilm properties of chemically synthesized silver nanoparticles found against Pseudomonas aeruginosa. Journal of nanobiotechnology. 12: 2. doi: 10.1186/1477-3155-12-2

Panwar, R., Pemmaraju, S.C., Sharma, A.K., Pruthi, V. 2016. Efficacy of ferulic acid encapsulated chitosan nanoparticles against Candida albicans biofilm. Microbial pathogenesis, 95: 21-31. doi: 10.1016/j.micpath.2016.02.007

Park, M.V., Neigh, A.M., Vermeulen, J.P., de la Fonteyne, L.J., Verharen, H.W., Briedé, J.J., van Loveren, H., and de Jong, W.H. 2011a. The effect of particle size on the cytotoxicity, inflammation, developmental toxicity and genotoxicity of silver nanoparticles. Biomaterials, 32(36): 9810-9817. doi: 

10.1016/j.biomaterials.2011.08.085.

Park, S., Park, Y., Hahm, K. 2011b. The role of antimicrobial peptides in preventing multidrug-resistant bacterial infections and biofilm formation. Int. J. Mol. Sci. 12(9): 5971-5992. doi: 10.3390/ijms12095971

Pelgrift, R.Y., and Friedman, A.J. 2013. Nanotechnology as a therapeutic tool to combat microbial resistance. Adv. Drug. Deliver. Rev. 65(13-14): 1803-1815. doi: 10.1016/j.addr.2013.07.011.

Perelshtein, I., Ruderman, E., Perkas, N., Tzanov, T., Beddow, J., Joyce, E., Mason, T.J., Blanes, M., Mollá, K., Patlolla, A., Frenkel, A.I., Gedanken, A..(2013) Chitosan and chitosan-ZnO-based complex nanoparticles: formation, characterization, and antibacterial activity. J. Mater. Chem. B. 1(14): 1968-1976. doi: 10.1039/C3TB00555K

Pérez-Díaz, M.A., Boegli, L., James, G., Velasquillo, C., Sánchez-Sánchez, R., Martínez-Martínez, R., Martínez-Castañón, G.A., Martinez-Gutierrez, F. 2015. Silver nanoparticles with antimicrobial activities against Streptococcus mutans and their cytotoxic effect. Materials Science and Engineering: C, 55: 360-366. doi: 10.1016/j.msec.2015.05.036

Prajna Jena, S.M.R.M. 2012. Toxicity and antibacterial assessment of chitosancoated silver nanoparticles on human pathogens and macrophage cells. Int $\mathrm{J}$ Nanomedicine. 7: 1805-1818. doi: 10.2147/IJN.S28077

Qayyum, S., Khan, A.U. 2016. Nanoparticles vs. biofilms: a battle against another paradigm of antibiotic resistance. Med. Chem. Commun. doi: 
1464

1465

1466

1467

1468

1469

1470

1471

1472

1473

1474

1475

1476

1477

1478

1479

1480

1481

1482

1483

1484

Qi, L., Xu, Z., Jiang, X., Hu, C., and Zou, X. 2004. Preparation and antibacterial activity of chitosan nanoparticles. Carbohydr. Res. 339(16): 2693-2700. doi: 10.1016/j.carres.2004.09.007.

Qi, X., Gunawan, P., Xu, R., Chang, M.W. 2012. Cefalexin-immobilized multi-walled carbon nanotubes show strong antimicrobial and anti-adhesion properties. Chemical engineering science, 84: 552-556. doi: 10.1016/j.ces.2012.08.054

Qi, X., Poernomo, G., Wang, K., Chen, Y., Chan-Park, M.B., Xu, R., Chang, M.W. 2011. Covalent immobilization of nisin on multi-walled carbon nanotubes: superior antimicrobial and anti-biofilm properties. Nanoscale. 3(4): 1874-1880. doi: 10.1039/C1NR10024F

Qu, X., Alvarez, P.J., and Li, Q. 2013. Applications of nanotechnology in water and wastewater treatment. Water Res. 47(12): 3931-3946. doi: 10.1016/j.watres.2012.09.058.

Qu, X., Brame, J., Li, Q., and Alvarez, P.J. 2012. Nanotechnology for a safe and sustainable water supply: enabling integrated water treatment and reuse. Acc. Chem. Res. 46(3): 834-843. doi: 10.1021/ar300029v.

Rabea, E.I., Badawy, M.E.-T., Stevens, C.V., Smagghe, G., and Steurbaut, W. 2003. Chitosan as antimicrobial agent: applications and mode of action. Biomacromolecules, 4(6): 1457-1465. doi: 10.1021/bm034130m.

Rahaman, M.S., Vecitis, C.D., and Elimelech, M. 2012. Electrochemical carbon-nanotube filter performance toward virus removal and inactivation in the 
1485

1486

1487

1488

1489

1490

1491

1492

1493

1494

1495

1496

1497

1498

1499

1500

1501

1502

1503

1504

1505

1506

presence of natural organic matter. Environ. Sci. Technol. 46(3): 1556-1564. doi: $10.1021 /$ es203607d.

Rai, M., Yadav, A., and Gade, A. 2009. Silver nanoparticles as a new generation of antimicrobials. Biotechnol. Adv. 27(1): 76-83. doi: 10.1016/j.biotechadv.2008.09.002.

Ramírez-Díaz, M.I., Díaz-Pérez, C., Vargas, E., Riveros-Rosas, H., Campos-García, J., Cervantes, C. 2008. Mechanisms of bacterial resistance to chromium compounds. Biometals. 21(3): 321-332. doi: 10.1007/s10534-007-9121-8

Rasmussen, J.W., Martinez, E., Louka, P., Wingett, D.G. 2010. Zinc oxide nanoparticles for selective destruction of tumor cells and potential for drug delivery applications. Expert opinion on drug delivery. 7(9): 1063-1077. doi: $10.1517 / 17425247.2010 .502560$

Rasmussen, T.B., Givskov, M. 2006. Quorum-sensing inhibitors as anti-pathogenic drugs. International Journal of Medical Microbiology. 296(2): 149-161. doi: 10.1016/j.ijmm.2006.02.005

Reddy, K.M., Feris, K., Bell, J., Wingett, D.G., Hanley, C., and Punnoose, A. 2007 a. Selective toxicity of zinc oxide nanoparticles to prokaryotic and eukaryotic systems. Appl. Phys. Lett. 90(21): 213902. doi: 10.1063/1.2742324.

Reddy, L.S., Nisha, M.M., Joice, M., and Shilpa, P. 2014. Antimicrobial activity of zinc oxide $(\mathrm{ZnO})$ nanoparticle against Klebsiella pneumoniae. Pharm. Biol. 52(11): 1388-1397. doi: 10.3109/13880209.2014.893001.

Reddy, M.P., Venugopal, A., and Subrahmanyam, M. $2007 \mathrm{~b}$. 
1507

1508

1509

1510

1511

1512

1513

1514

1515

1516

1517

1518

1519

1520

1521

1522

1523

1524

1525

1526

1527

1528

Hydroxyapatite-supported $\mathrm{Ag}-\mathrm{TiO}_{2}$ as Escherichia coli disinfection photocatalyst. Water Res. 41(2): 379-386. doi: 10.1016/j.watres.2006.09.018.

Ren, J., Han, P., Wei, H., and Jia, L. 2014. Fouling-resistant behavior of silver nanoparticle-modified surfaces against the bioadhesion of microalgae. ACS Appl. Mater. Interfaces, 6(6): 3829-3838. doi: 10.1021/am500292y.

Roberts, A.P., Mount, A.S., Seda, B., Souther, J., Qiao, R., Lin, S., Ke, P.C., Rao, A.M., and Klaine, S.J. 2007. In vivo biomodification of lipid-coated carbon nanotubes by Daphnia magna. Environ. Sci. Technol. 41(8): 3025-3029. doi: $10.1021 /$ es $062572 a$.

Rodrigues, D.F., and Elimelech, M. 2010. Toxic effects of single-walled carbon nanotubes in the development of E. coli biofilm. Environ. Sci. Technol. 44(12): 4583-4589. doi: 10.1021/es1005785.

Roe, D., Karandikar, B., Bonn-Savage, N., Gibbins, B., Roullet, J. 2008. Antimicrobial surface functionalization of plastic catheters by silver nanoparticles. J. Antimicrob. Chemother. 61(4): 869-876. doi: 10.1093/jac/dkn034

Salta, M., Wharton, J.A., Stoodley, P., Dennington, S.P., Goodes, L.R., Werwinski, S., Mart, U., Wood, R.J., Stokes, K.R. 2010. Designing biomimetic antifouling surfaces. Philosophical Transactions of the Royal Society of London A: Mathematical, Physical and Engineering Sciences. 368(1929): 4729-4754. doi: $10.1098 /$ rsta.2010.0195

Sathyanarayanan, M.B., Balachandranath, R., Genji Srinivasulu, Y., Kannaiyan, S.K., Subbiahdoss, G., 2013. The Effect of Gold and Iron-Oxide Nanoparticles on 
Biofilm-Forming Pathogens. ISRN Microbiol. 2013: 1-5. doi:

1530

1531

1532

1533

1534

1535

1536

1537

1538

1539

1540

1541

1542

1543

1544

1545

1546

1547

1548

1549

1550

$10.1155 / 2013 / 272086$

Sawai, J. 2003. Quantitative evaluation of antibacterial activities of metallic oxide powders $(\mathrm{ZnO}, \mathrm{MgO}$ and $\mathrm{CaO})$ by conductimetric assay. J. Microbiol. Methods, 54(2): 177-182. doi: 10.1016/S0167-7012(03)00037-X.

Sawai, J., Shoji, S., Igarashi, H., Hashimoto, A., Kokugan, T., Shimizu, M., and Kojima, H. 1998. Hydrogen peroxide as an antibacterial factor in zinc oxide powder slurry. J. Ferment. Bioeng. 86(5): 521-522. doi: 10.1016/S0922-338X(98)80165-7.

Sayes, C.M., Gobin, A.M., Ausman, K.D., Mendez, J., West, J.L., and Colvin, V.L. 2005. Nano- $\mathrm{C}_{60}$ cytotoxicity is due to lipid peroxidation. Biomaterials, 26(36): 7587-7595. doi: 10.1016/j.biomaterials.2005.05.027.

Service, R. 1998. CHEMISTRY: Nanotubes: The Next Asbestos? Science, 281(5379): 941-941.

Shahrokh, S., Emtiazi, G. 2013. A comparative study of the effects of colloidal nanosilver and industrial biocide E-265 on bacterial respiration and biofilm formation using microtiterplate method. J Water Wastewater. 24(85): 26-33.

Shahverdi, A.R., Fakhimi, A., Shahverdi, H.R., and Minaian, S. 2007. Synthesis and effect of silver nanoparticles on the antibacterial activity of different antibiotics against Staphylococcus aureus and Escherichia coli. Nanomedicine, 3(2): 168-171. doi: 10.1016/j.nano.2007.02.001.

Shanthi, S., Jayaseelan, B.D., Velusamy, P., Vijayakumar, S., Chih, C.T., Vaseeharan, 
1551

1552

1553

1554

1555

1556

1557

1558

1559

1560

1561

1562

1563

1564

1565

1566

1567

1568

1569

1570

1571

1572

B. 2016. Biosynthesis of silver nanoparticles using a probiotic Bacillus licheniformis Dahb1 and their antibiofilm activity and toxicity effects in Ceriodaphnia cornuta. Microbial pathogenesis, 93: 70-77. doi: 10.1016/j.micpath.2016.01.014

Sheng, Z., Liu, Y., 2011. Effects of silver nanoparticles on wastewater biofilms. Water Research. 45(18): 6039-6050. doi: 10.1016/j.watres.2011.08.065

Shi, L.E., Li, Z.H., Zheng, W., Zhao, Y.F., Jin, Y.F., and Tang, Z.X. 2014. Synthesis, antibacterial activity, antibacterial mechanism and food applications of $\mathrm{ZnO}$ nanoparticles: a review. Food additives \& contaminants. Part A, 31(2): 173-186. doi: 10.1080/19440049.2013.865147.

Shirakawa, M.A., John, V.M., Mocelin, A., Zilles, R., Toma, S.H., Araki, K., Toma, H.E., Thomaz, A.C., Gaylarde, C.C. 2016. Effect of silver nanoparticle and TiO 2 coatings on biofilm formation on four types of modern glass. International Biodeterioration \& Biodegradation, 108: 175-180. doi: 10.1016/j.ibiod.2015.12.025

Shrestha, A., Hamblin, M.R., Kishen, A. 2014. Photoactivated rose bengal functionalized chitosan nanoparticles produce antibacterial/biofilm activity and stabilize dentin-collagen. Nanomedicine: Nanotechnology, Biology and Medicine. 10(3): 491-501. doi: 10.1016/j.nano.2013.10.010

Shrivastava, S., Bera, T., Roy, A., Singh, G., Ramachandrarao, P., and Dash, D. 2007. Characterization of enhanced antibacterial effects of novel silver nanoparticles. Nanotechnology, 18(22): 225103. doi: 10.1088/0957-4484/18/22/225103. 
1573

1574

1575

1576

1577

1578

1579

1580

1581

1582

1583

1584

1585

1586

1587

1588

1589

1590

1591

1592

1593

1594

Sihorkar, V., Vyas, S.P. 2001. Biofilm consortia on biomedical and biological surfaces: delivery and targeting strategies. Pharm Res. 18: 9, 1247-1254. doi: 10.1023/A:1013073508318

Silva, S., Pires, P., Monteiro, D.R., Negri, M., Gorup, L.F., Camargo, E.R., Barbosa, D.B., Oliveira, R., Williams, D.W., Henriques, M. 2013. The effect of silver nanoparticles and nystatin on mixed biofilms of Candida glabrata and Candida albicans on acrylic. Medical mycology. 51(2): 178-184. doi: 10.3109/13693786.2012.700492.

Silver, S., Phung, L.T., Silver, G. 2006. Silver as biocides in burn and wound dressings and bacterial resistance to silver compounds. J Ind Microbiol Biotechnol. 33(7): 627-634. doi: 10.1007/s10295-006-0139-7

Simões, M., Bennett, R.N., and Rosa, E.A. 2009. Understanding antimicrobial activities of phytochemicals against multidrug resistant bacteria and biofilms. Nat. Prod. Rep. 26(6): 746-757. doi: 10.1039/B821648G.

Simões, M., Simões, L.C., and Vieira, M.J. 2010. A review of current and emergent biofilm control strategies. LWT - Food Sci. Technol. 43(4): 573-583. doi: 10.1016/j.lwt.2009.12.008.

Singh, A., Ahmed, A., Prasad, K.N., Khanduja, S., Singh, S.K., Srivastava, J.K., Gajbhiye, N.S. 2015a. Antibiofilm and Membrane-Damaging Potential of Cuprous Oxide Nanoparticles against Staphylococcus aureus with Reduced Susceptibility to Vancomycin. Antimicrob. Agents Chemother. 59(11): 6882-6890. doi: 10.1128/AAC.01440-15 
1595

1596

1597

1598

1599

1600

1601

1602

1603

1604

1605

1606

1607

1608

1609

1610

1611

1612

1613

1614

1615

1616

Singh, B.N., Pandey, G., Jadaun, V., Singh, S., Bajpai, R., Nayaka, S., Naqvi, A.H., Rawat, A.K.S., Upreti, D.K., Singh, B.R. 2015b. Development and characterization of a novel Swarna-based herbo-metallic colloidal nano-formulation-inhibitor of Streptococcus mutans quorum sensing. RSC Adv. 5(8): 5809-5822. doi: 10.1039/C4RA11939H

Singh, B.R., Singh, B.N., Singh, A., Khan, W., Naqvi, A.H., Singh, H.B. 2015c. Mycofabricated biosilver nanoparticles interrupt Pseudomonas aeruginosa quorum sensing systems. Sci Rep. 5: 13719. doi: 10.1038/srep13719

Skraber, S., Schijven, J., Gantzer, C., de Roda Husman, A.M. 2005. Pathogenic viruses in drinking-water biofilms: a public health risk? Biofilms. 2(02): 105-117. doi: $10.1017 / \mathrm{S} 1479050505001833$

Srivastava, A., Srivastava, O., Talapatra, S., Vajtai, R., and Ajayan, P. 2004. Carbon nanotube filters. Nat. Mater. 3(9): 610-614. doi: 10.1038/nmat1192.

Srivastava, N.K., Majumder, C.B. 2008. Novel biofiltration methods for the treatment of heavy metals from industrial wastewater. Journal of hazardous materials. 15(1): 1-8. doi: 10.1016/j.jhazmat.2007.09.101

Sun, T., Qing, G. 2011. Biomimetic smart interface materials for biological applications. Advanced Materials. 23(12). doi: 10.1002/adma.201004326

Sundheim, G., Langsrud, S., Heir, E., Holck, A.L. 1998. Bacterial resistance to disinfectants containing quaternary ammonium compounds. Int Biodeter Biodegr. 41(3): 235-239. doi: 10.1016/S0964-8305(98)00027-4

Taglietti, A., Arciola, C.R., D'Agostino, A., Dacarro, G., Montanaro, L., Campoccia, 
1617

1618

1619

1620

1621

1622

1623

1624

1625

1626

1627

1628

1629

1630

1631

1632

1633

1634

1635

1636

1637

1638

D., Cucca, L., Vercellino, M., Poggi, A., Pallavicini, P. 2014. Antibiofilm activity of a monolayer of silver nanoparticles anchored to an amino-silanized glass surface. Biomaterials. 35(6): 1779-1788. doi: 10.1016/j.biomaterials.2013.11.047

Tan, Y., Ma, S., Liu, C., Yu, W., Feng, H. 2015. Enhancing the stability and antibiofilm activity of DspB by immobilization on carboxymethyl chitosan nanoparticles. Microbiological research, 178: 35-41. doi: 10.1016/j.micres.2015.06.001.

Tavaria, F.K., Costa, E.M., Gens, E.J., Malcata, F.X., and Pintado, M.E. 2013. Influence of abiotic factors on the antimicrobial activity of chitosan. J. Dermatol. 40(12): 1014-1019. doi: 10.1111/1346-8138.12315.

Tawale, J., Dey, K., Pasricha, R., Sood, K., and Srivastava, A. 2010. Synthesis and characterization of $\mathrm{ZnO}$ tetrapods for optical and antibacterial applications. Thin Solid Films, 519(3): 1244-1247. doi: 10.1016/j.tsf.2010.08.077.

Tegos, G.P., Demidova, T.N., Arcila-Lopez, D., Lee, H., Wharton, T., Gali, H., and Hamblin, M.R. 2005. Cationic fullerenes are effective and selective antimicrobial photosensitizers. Chem. Biol. 12(10): 1127-1135. doi: 10.1016/j.chembiol.2005.08.014.

Thallinger, B., Prasetyo, E.N., Nyanhongo, G.S., Guebitz, G.M. 2013. Antimicrobial enzymes: an emerging strategy to fight microbes and microbial biofilms. Biotechnology journal. 8(1): 97-109. doi: 10.1002/biot.201200313

Thukkaram, M., Sitaram, S., Subbiahdoss, G. 2014. Antibacterial efficacy of iron-oxide nanoparticles against biofilms on different biomaterial surfaces. International journal of biomaterials. doi: 10.1155/2014/716080 
1639 Tiede, K., Boxall, A.B., Tear, S.P., Lewis, J., David, H., and Hassellöv, M. 2008. 1640 Detection and characterization of engineered nanoparticles in food and the

1641

1642

1643

1644

1645

1646

1647

1648

1649

1650

1651

1652

1653

1654

1655

1656

1657

1658

1659

1660 environment. Food Addit. Contam. 25(7): 795-821. doi: $10.1080 / 02652030802007553$.

Tikhonov, V.E., Stepnova, E.A., Babak, V.G., Yamskov, I.A., Palma-Guerrero, J., Jansson, H.-B., Lopez-Llorca, L.V., Salinas, J., Gerasimenko, D.V., and Avdienko, I.D. 2006. Bactericidal and antifungal activities of a low molecular weight chitosan and its N-/2 (3)-(dodec-2-enyl) succinoyl/-derivatives. Carbohydr. Polym. 64(1): 66-72. doi: 10.1016/j.carbpol.2005.10.021.

Tin, S., Sakharkar, K.R., Lim, C.S., and Sakharkar, M.K. 2009. Activity of Chitosans in combination with antibiotics in Pseudomonas aeruginosa. Int. J. Biol. Sci. 5(2): 153. doi: 10.7150/ijbs.5.153.

Tiraferri, A., Vecitis, C.D., Elimelech, M. 2011. Covalent binding of single-walled carbon nanotubes to polyamide membranes for antimicrobial surface properties. ACS Appl. Mater. Interfaces. 3(8): 2869-2877. doi: 10.1021/am200536p

Tong, Z., Bischoff, M., Nies, L.F., Carroll, N.J., Applegate, B., Turco, R.F. 2016. Influence of fullerene (C60) on soil bacterial communities: aqueous aggregate size and solvent co-introduction effects. Sci Rep. 6. doi: 10.1038/srep28069

Tripathy, N., Ahmad, R., Bang, S.H., Khang, G., Min, J., Hahn, Y. 2016. Outstanding Antibiofilm Features of Quanta-CuO Film on Glass Surface. ACS Appl. Mater. Interfaces. 8 (24): 15128-15137. doi: 10.1021/acsami.6b04494

Tsao, N., Luh, T.-Y., Chou, C.-K., Chang, T.-Y., Wu, J.-J., Liu, C.-C., and Lei, H.-Y. 
1661

1662

1663

1664

1665

1666

1667

1668

1669

1670

1671

1672

1673

1674

1675

1676

1677

1678

1679

1680

1681

1682

2002. In vitro action of carboxyfullerene. J. Antimicrob. Chemother. 49(4): 641-649. doi: 10.1093/jac/49.4.641.

Vamathevan, V., Amal, R., Beydoun, D., Low, G., and McEvoy, S. 2004. Silver metallisation of titania particles: effects on photoactivity for the oxidation of organics. Chem. Eng. J. 98(1): 127-139. doi: 10.1016/j.cej.2003.05.004.

Vaseeharan, B., Sivakamavalli, J., Thaya, R. 2015. Synthesis and characterization of chitosan- $\mathrm{ZnO}$ composite and its antibiofilm activity against aquatic bacteria. Journal of Composite Materials, 49(2): 177-184. doi: $10.1177 / 0021998313515289$

Vecitis, C.D., Schnoor, M.H., Rahaman, M.S., Schiffman, J.D., and Elimelech, M. 2011. Electrochemical multiwalled carbon nanotube filter for viral and bacterial removal and inactivation. Environ. Sci. Technol. 45(8): 3672-3679. doi: 10.1021/es2000062.

Vecitis, C.D., Zodrow, K.R., Kang, S., and Elimelech, M. 2010. Electronic-structure-dependent bacterial cytotoxicity of single-walled carbon nanotubes. ACS nano, 4(9): 5471-5479. doi: 10.1021/nn101558x.

Venkadesaperumal, G., Rucha, S., Sundar, K., Shetty, P.H. 2016. Anti-quorum sensing activity of spice oil nanoemulsions against food borne pathogens. LWT - Food Science and Technology, 66: 225-231. doi:10.1016/j.lwt.2015.10.044

Wagh, M.S., Patil, R.H., Thombre, D.K., Kulkarni, M.V., Gade, W.N., Kale, B.B. 2013. Evaluation of anti-quorum sensing activity of silver nanowires. Appl Microbiol Biotechnol. 97(8): 3593-3601. doi: 10.1007/s00253-012-4603-1 
1683

1684

1685

1686

1687

1688

1689

1690

1691

1692

1693

1694

1695

1696

1697

1698

1699

1700

1701

1702

1703

1704

Wei, D., Sun, W., Qian, W., Ye, Y., Ma, X. 2009. The synthesis of chitosan-based silver nanoparticles and their antibacterial activity. Carbohydrate Research. 344(17): 2375-2382. doi: 10.1016/j.carres.2009.09.001

Wen, H.-C., Lin, Y.-N., Jian, S.-R., Tseng, S.-C., Weng, M.-X., Liu, Y.-P., Lee, P.-T., Chen, P.-Y., Hsu, R.-Q., and Wu, W.-F. 2007. Observation of growth of human fibroblasts on silver nanoparticles. J. Phys.: Conf. Ser. IOP Publishing. 61(1): 445. doi: $10.1088 / 1742-6596 / 61 / 1 / 089$.

Wingender, J., Flemming, H. 2011. Biofilms in drinking water and their role as reservoir for pathogens. Int J Hyg Envir Heal. 214(6): 417-423. doi: 10.1016/j.ijheh.2011.05.009

Wong, M.-S., Chu, W.-C., Sun, D.-S., Huang, H.-S., Chen, J.-H., Tsai, P.-J., Lin, N.-T., Yu, M.-S., Hsu, S.-F., and Wang, S.-L. 2006. Visible-light-induced bactericidal activity of a nitrogen-doped titanium photocatalyst against human pathogens. Appl. Environ. Microbiol. 72(9): 6111-6116. doi: 10.1128/AEM.02580-05.

Wu, P., Xie, R., Imlay, K., and Shang, J.K. 2010. Visible-light-induced bactericidal activity of titanium dioxide codoped with nitrogen and silver. Environ. Sci. Technol. 44(18): 6992-6997. doi: 10.1021/es101343c.

Xie, Y., He, Y., Irwin, P.L., Jin, T., and Shi, X. 2011. Antibacterial activity and mechanism of action of zinc oxide nanoparticles against Campylobacter jejuni. Appl. Environ. Microbiol. 77(7): 2325-2331. doi: 10.1128/AEM.02149-10.

Xiu, Z.-m., Zhang, Q.-b., Puppala, H.L., Colvin, V.L., and Alvarez, P.J. 2012. Negligible particle-specific antibacterial activity of silver nanoparticles. Nano 

Lett. 12(8): 4271-4275. doi: 10.1021/nl301934w.

Yamamoto, O. 2001. Influence of particle size on the antibacterial activity of zinc oxide. Int. J. Inorg. Mater. 3(7): 643-646. doi: 10.1016/S1466-6049(01)00197-0.

Yang, C., Mamouni, J., Tang, Y., and Yang, L. 2010. Antimicrobial activity of single-walled carbon nanotubes: length effect. Langmuir, 26(20): 16013-16019. doi: $10.1021 / \mathrm{la} 103110 \mathrm{~g}$.

Yavuz, C.T., Mayo, J., William, W.Y., Prakash, A., Falkner, J.C., Yean, S., Cong, L., Shipley, H.J., Kan, A., and Tomson, M. 2006. Low-field magnetic separation of monodisperse $\mathrm{Fe}_{3} \mathrm{O}_{4}$ nanocrystals. Science, 314(5801): 964-967. doi: 10.1126/science. 1131475 .

Yien, L., Zin, N.M., Sarwar, A., Katas, H., 2012. Antifungal activity of chitosan nanoparticles and correlation with their physical properties. International journal of biomaterials. 2012: 632698. doi: 10.1155/2012/632698

Yoon, K.-Y., Byeon, J.H., Park, J.-H., and Hwang, J. 2007. Susceptibility constants of Escherichia coli and Bacillus subtilis to silver and copper nanoparticles. Sci. Total Environ. 373(2): 572-575. doi: 10.1016/j.scitotenv.2006.11.007.

Zhang, L., Ding, Y., Povey, M., and York, D. 2008. ZnO nanofluids-A potential antibacterial agent. Prog. Nat. Sci. 18(8): 939-944. doi: 10.1016/j.pnsc.2008.01.026.

Zhang, L., Jiang, Y., Ding, Y., Povey, M., and York, D. 2007. Investigation into the antibacterial behaviour of suspensions of $\mathrm{ZnO}$ nanoparticles ( $\mathrm{ZnO}$ nanofluids). J. Nanopart. Res. 9(3): 479-489. doi: 10.1007/s11051-006-9150-1. 
1727 Zhang, M., Zhang, K., De Gusseme, B., Verstraete, W., Field, R. 2014. The 1728 antibacterial and anti-biofouling performance of biogenic silver nanoparticles by 1729 Lactobacillus fermentum. Biofouling. 30(3): 347-357. doi: $1730 \quad 10.1080 / 08927014.2013 .873419$

1731 Zhang, Y., Dai, T., Wang, M., Vecchio, D., Chiang, L.Y., Hamblin, M.R. 2015. 1732 Potentiation of antimicrobial photodynamic inactivation mediated by a cationic 1733 fullerene by added iodide: in vitro and in vivo studies. Nanomedicine. 10(4): 1734 603-614. doi: 10.2217/nnm.14.131

1735 
1736

1737

1738

1739

1740

1741

1742

1743

1744

1745

1746

1747

1748

1749

1750

1751

\section{Figure legends:}

Figure 1. A schematic representation of the steps a new bacterial species takes in forming a biofilm on a substrate. First, the grey bacteria represent an aquatic species that swim towards the substrate and bind reversibly to the surface. And then the bacteria secrete binding molecules such as adhesion proteins that cause irreversible attachment. Once settled, the bacteria proliferate and form microcolonies, which lead to the development of a mature biofilm. Once the environmental conditions become unfavorable, equilibrium exists between the accumulation and detachment.

Figure 2. Various antimicrobial mechanisms exerted by NMs. Multiple mechanisms of antimicrobial action of chitosan-containing NPs (chitosan), silver-containing NPs (Ag NPs), zinc oxide-containing NPs (ZnO NPs), titanium dioxide-containing NPs $\left(\mathrm{TiO}_{2} \mathrm{NPs}\right)$, and carbon based NPs (CNTs and Fullerenes). ROS refers to reactive oxygen species. 


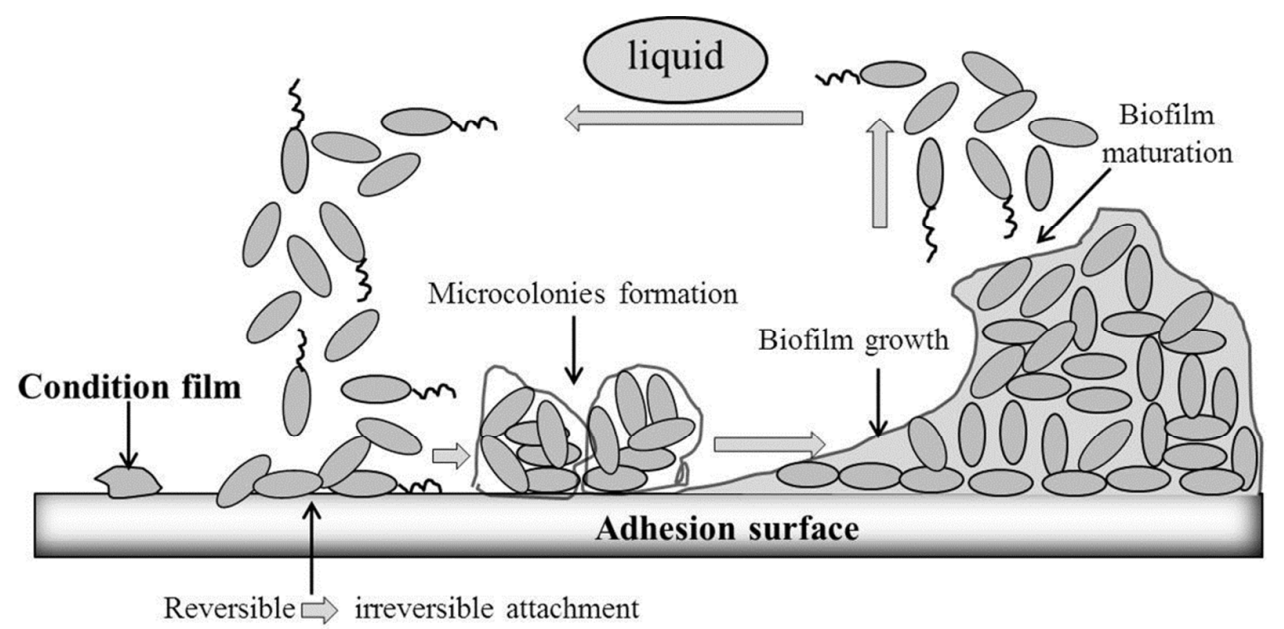

Figure 1. 


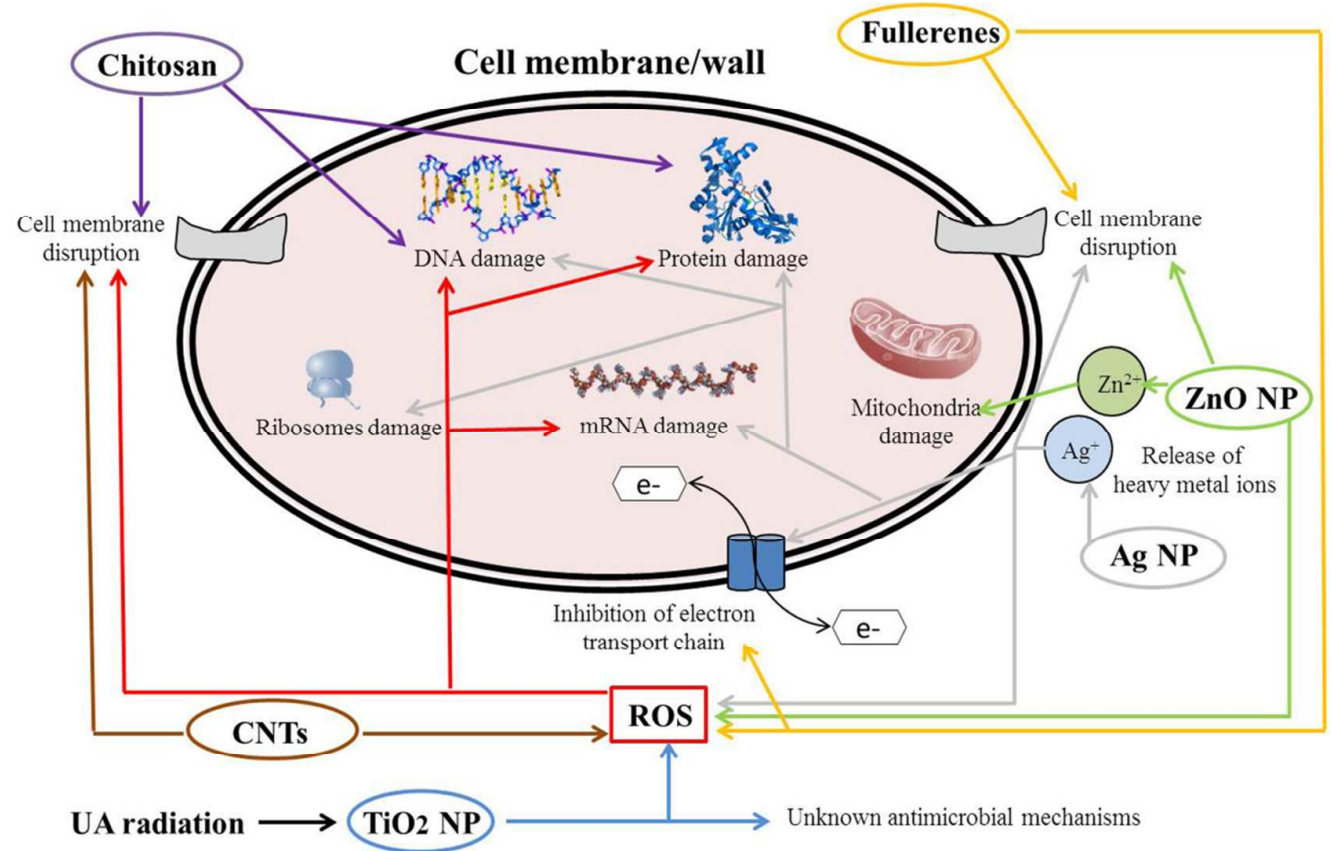

Figure 2. 
Table 1. Anmicrobial activity of NMs.

\begin{tabular}{|c|c|c|}
\hline Type of NMs & Target organism & Ref. \\
\hline \multicolumn{3}{|l|}{ Metals NPs } \\
\hline Ag NPs & $\begin{array}{l}\text { methicillin resistance Staphylococcus aureus (MRSA), methicillin } \\
\text { resistance Staphyloccus epidermidis (MRSE) }\end{array}$ & Ansari et al. 2015 \\
\hline Ag NPs & $\begin{array}{l}\text { multidrug-resistant } \begin{array}{l}\text { Pseudomonas aeruginosa, ampicillin-resistant } \\
\text { Escherichia coli } \\
\text { pyogenes }\end{array} \\
\text { O157:H7, erythromycin-resistant Streptococcus }\end{array}$ & Lara et al. 2010 \\
\hline Ag NPs & Staphylococcus aureus, Escherichia coli & Shahverdi et al. 2007 \\
\hline Ag NPs & Escherichia coli & Xiu et al. 2012 \\
\hline Ag NPs $\left(\mathrm{Bio}-\mathrm{Ag}^{0-6}\right)$ & Pseudomonas aeruginosa ATCC 27853 & Zhang et al. 2014 \\
\hline $\begin{array}{l}\text { ELE-Ag NPs synthesized by } \\
\text { using aqueous leaf extract of } \\
\text { Eucalyptus globulus (ELE) }\end{array}$ & $\begin{array}{l}\text { Pseudomonas aeruginosa, Escherichia coli, methicillin-resistant } \\
\text { Staphylococcus aureus (MRSA), methicillin-sensitive Staphylococcus } \\
\text { aureus (MSSA) }\end{array}$ & Ali et al. 2015 \\
\hline Starch-stabilized Ag NPs & $\begin{array}{l}\text { Staphylococcus aureus, Pseudomonas aeruginosa PAO1, Shigella } \\
\text { flexneri, Salmonella typhi, Mycobacterium smegmatis }\end{array}$ & Mohanty et al. 2012 \\
\hline Silver-carbene complex (SCC10) & Pseudomonas aeruginosa & Hindi et al. 2009 \\
\hline $\begin{array}{l}\text {-loaded into l-tyrosine } \\
\text { polyphosphate NPs }\end{array}$ & & \\
\hline $\begin{array}{l}\text { Silver carbene complexes (SCC) } \\
\text { NPs }\end{array}$ & $\begin{array}{l}\text { methicillin-resistant Staphylococcus aureus (MRSA), multidrug resistant } \\
\text { Acinetobacter baumannii (MRAB), }\end{array}$ & Leid et al. 2012 \\
\hline
\end{tabular}


Bacillus anthracis, Yersinia pestis

$\mathrm{Ag}-\mathrm{TiO}_{2}$ nanocomposites

Ag NPs, ZnO NPs

Ag NPs, CuO NPs

$\mathrm{TiO}_{2}$ photocatalysis

$\mathrm{TiO}_{2}$ photocatalysis

$\mathrm{TiO}_{2}$ photocatalysis

$\mathrm{TiO}_{2}$ photocatalysis

Nanosized $\mathrm{TiO}_{2}$

$\mathrm{TiO}_{2}, \mathrm{SiO}_{2}, \mathrm{ZnO}$ NPs

Nitrogen-doped $\mathrm{TiO}_{2}$

$\mathrm{TiO}_{2}$ NPs codoped with nitrogen and silver $\left(\mathrm{Ag}_{2} \mathrm{O} / \mathrm{TiON}\right)$

$\mathrm{ZnO}$ NPs

$\mathrm{ZnO}$ NPs

$\mathrm{ZnO}$ NPs

$\mathrm{ZnO}$ NPs

$\mathrm{ZnO}$ NPs

$\mathrm{ZnO}$ NPs

$\mathrm{ZnO}$ NPs

Escherichia coli, Bacillus subtilis

Escherichia coli

Kocuria rhizophila

Staphylococcus aureus Acinetobacter baumannii

Escherichia coli AN 387

Escherichia coli

Pseudomonas aeruginosa

Pseudomonas aeruginosa

Escherichia coli $\mathrm{O} 157: \mathrm{H} 7$

Escherichia coli $\mathrm{DH} 5 \alpha$
Bacillus subtilis IC12488, Staphylococcus aureus IC13204, Escherichia Lungu et al. 2014 coli IC13147 and IC13529, Klebsiella pneumoniae 1204 and IC13420

Streptococcus mutans, Lactobacillus

Kasraei et al. 2014

Yoon et al. 2007

Escherichia coli, Lactobacillus acidophilus

Escherichia coli

Benabbou et al. 2007

Choi et al. 2007a, 2007b

Gogniat and Dukan 2007

Muranyi et al. 2010

Escherichia coli, Pseudomonas aeruginosa, Klebsiella pneumoniae, Desai and Kowshik 2009

Escherichia coli DH5a, Bacillus subtilis CB310

Adams et al. 2006

Escherichia coli, Shigella flexneri, Listeria monocytogenes, Vibrio parahaemolyticus, Staphylococcus aureus, Streptococcus pyogenes,

Wu et al. 2010

Dutta et al. 2010

Dwivedi et al. 2014

Botrytis cinerea, Penicillium expansum

He et al. 2011

Jones et al. 2008

Lee et al. 2014
Liu et al. 2009b

Padmavathy

Vijayaraghavan 2016 


\begin{tabular}{|c|c|c|}
\hline $\mathrm{ZnO} \mathrm{NPs}$ & $\begin{array}{l}\text { Salmonella paratyphi B, Klebsiella pneumoniae MTCC109, Bacillus } \\
\text { subtilis MTCC441, Enterobacter aerogenes MTCC111, Staphylococcus } \\
\text { epidermidis MTCC } 3615 \text {, Methicillin resistant-MRSA, Candida albicans } \\
\text { MTCC } 227 \text {, Malassezia pachydermatis }\end{array}$ & Palanikumar et al. 2014 \\
\hline $\mathrm{ZnO} \mathrm{NPs}$ & Campylobacter jejuni & Xie et al. 2011 \\
\hline $\mathrm{ZnO}$ nanofluids & Escherichia coli & Zhang et al. 2007, 2008 \\
\hline ZnO powders & $\begin{array}{l}\text { Staphylococcus aureus, } \\
\text { Escherichia coli }\end{array}$ & Yamamoto 2001 \\
\hline $\begin{array}{l}\mathrm{ZnO} \quad \text { powder } \\
\text { crystallographic }\end{array}$ & Escherichia coli, Staphylococcus aureus & Ohira et al. 2008 \\
\hline Zinc oxide quantum dots NPs & $\begin{array}{l}\text { Listeria monocytogenes, Salmonella Enteritidis, Escherichia coli } \\
\text { O157:H7 }\end{array}$ & Jin et al. 2009 \\
\hline $\mathrm{ZnO}$ tetrapods & Escherichia coli, Staphylococcus aureus, Candida albicans & Tegos et al. 2005 \\
\hline $\begin{array}{lll}\text { Gold-based } \quad \text { zinc } & \text { oxide } \\
\text { nanostructures }(\mathrm{Au} @ \mathrm{ZnO}) & \end{array}$ & Pseudomonas aeruginosa & Gholap et al. 2016 \\
\hline $\mathrm{Zn} / \mathrm{Fe}$ oxide composite NPs & Staphylococcus aureus, Escherichia coli & Gordon et al. 2011 \\
\hline $\begin{array}{l}\text { Plant Mediated Gold NPs using } \\
\text { Garcinia cambogia }\end{array}$ & $\begin{array}{l}\text { Bacillus subtilis, Escherichia coli, Listeria monocytogenes, Proteus } \\
\text { vulgaris, Vibryo parahaemolyticus }\end{array}$ & Nithya and Jayachitra 2016 \\
\hline \multicolumn{3}{|c|}{ Naturally occurring antimicrobial substances based NMs } \\
\hline Natural compound chitosan & Escherichia coli, Staphylococcus aureus & Chung et al. 2003 \\
\hline Natural compound chitosan & Staphylococcus aureus, Escherichia coli & Fernandes et al. 2008 \\
\hline Natural compound chitosan & Burkholderia cenocepacia & Ibrahim et al. 2014 \\
\hline Natural compound chitosan & Staphylococcus aureus, Staphylococcus epidermidis, Escherichia coli & Tavaria et al. 2013 \\
\hline Natural compound chitosan & $\begin{array}{l}\text { Escherichia coli, Pseudomonas aureofaciens, Enterobacter agglomerans, } \\
\text { Bacillus subtilis, Candida kruisei, Fusarium oxysporum f. sp. radicis } \\
\text { lycopersici }\end{array}$ & Tikhonov et al. 2006 \\
\hline
\end{tabular}




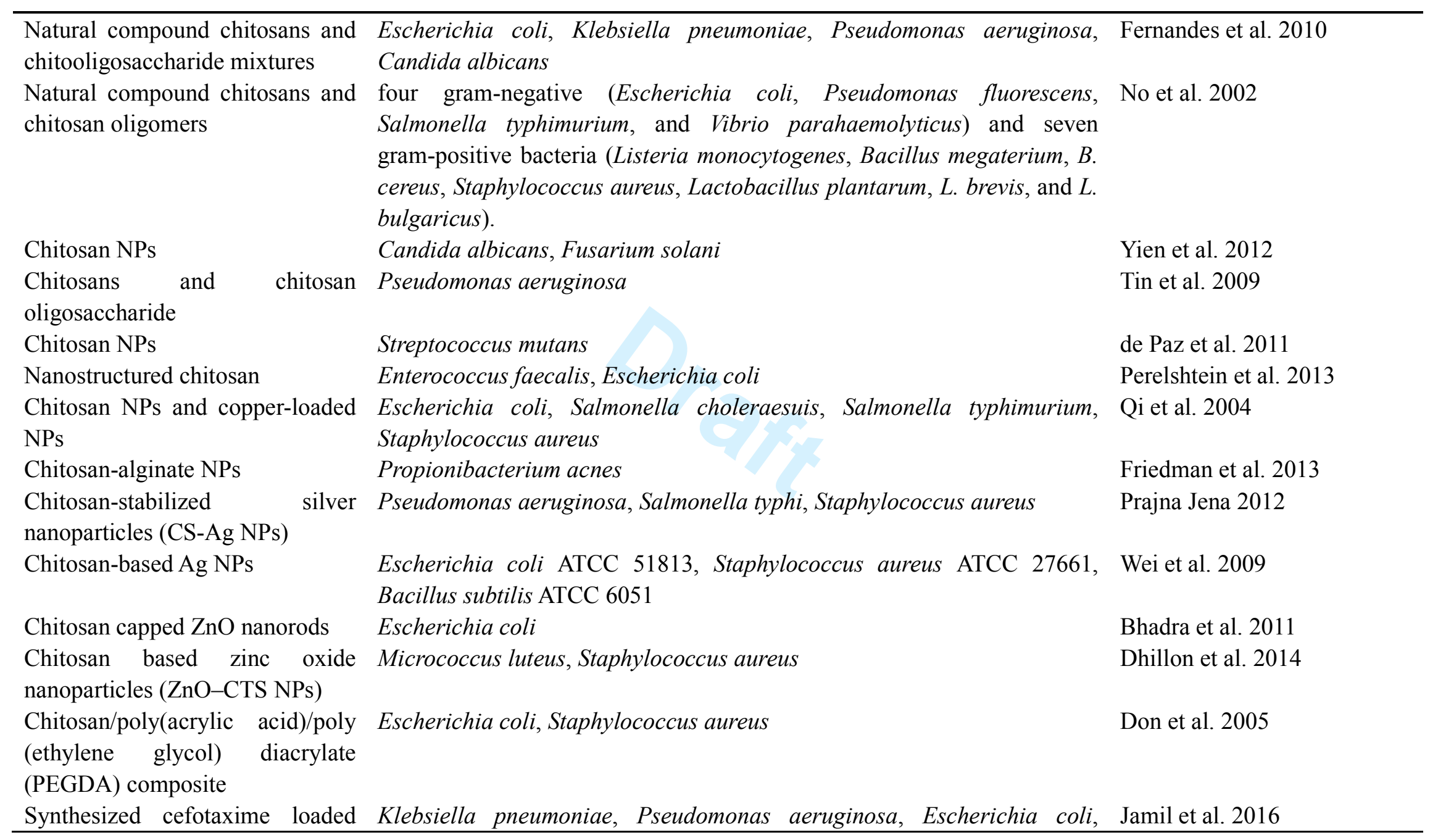




\begin{tabular}{|c|c|c|}
\hline $\begin{array}{l}\text { chitosan based nano-antibiotics } \\
\text { Carbon-based NMs }\end{array}$ & methicillin resistant Staphylococcus aureus & \\
\hline $\begin{array}{l}\text { O-carbon nanotubes (CNTs) / } \\
\text { poly (vinyl alcohol) (PVOH) } \\
\text { nanocomposites }\end{array}$ & Pseudomonas aeruginosa & Goodwin Jr et al., 2015 \\
\hline $\begin{array}{l}\text { Single-walled carbon nanotubes } \\
\text { (SWCNTs) and multi-walled } \\
\text { carbon nanotubes (MWCNTs) }\end{array}$ & Escherichia coli & Kang et al. 2008 \\
\hline SWCNTs & Salmonella typhimurium, Bacillus subtilis, Staphylococcus aureus & Arias et al. 2009 \\
\hline SWCNTs & Escherichia coli $\mathrm{K} 12$, Bacteriophage MS2 & Brady-Estévez et al. 2008 \\
\hline SWCNTs & Bacteriophage MS2 & Brady-Estévez et al. 2010 \\
\hline SWCNTs & Salmonella enterica, Escherichia coli & Dong et al. 2012 \\
\hline SWCNTs & Escherichia coli $\mathrm{K} 12$ & Kang et al. 2007 \\
\hline SWCNTs & $\begin{array}{l}\text { Escherichia coli, Pseudomonas aeruginosa, Staphylococcus aureus, } \\
\text { Bacillus subtilis }\end{array}$ & Liu et al. 2009a \\
\hline SWCNTs & Escherichia coli $\mathrm{K} 12 \mathrm{TG} 1$, Photobacterium leiognathi & Obraztsova et al. 2009 \\
\hline SWCNTs & Escherichia coli & Tiraferri et al. 2011 \\
\hline SWCNTs & Escherichia coli & Vecitis et al. 2010 \\
\hline SWCNTs & Salmonella typhimurium & Yang et al. 2010 \\
\hline $\begin{array}{l}\text { SWCNTs incorporated within the } \\
\text { biomedical polymer poly } \\
\text { (lactic-co-glycolic acid) (PLGA) }\end{array}$ & Escherichia coli, Staphylococcus epidermidis & Aslan et al. 2010 \\
\hline MWCNTs & viruses MS2, Escherichia coli & Vecitis et al. 2011 \\
\hline Nisin-coated MWCNTs sheet & Bacillus anthracis & Dong et al. 2014 \\
\hline MWCNTs -cefalexin composite & $\begin{array}{l}\text { Escherichia coli, Pseudomonas aeruginosa, Staphylococcus aureus, } \\
\text { Bacillus subtilis }\end{array}$ & Qi et al. 2012 \\
\hline
\end{tabular}




\begin{tabular}{lll}
\hline MWCNTs-nisin composite & Escherichia coli, Pseudomonas aeruginosa, Staphylococcus aureus, & Qi et al. 2011 \\
& Bacillus subtilis & \\
Fullerenes (C60) & Escherichia coli, Staphylococcus aureus & Alekseeva et al. 2014 \\
Fullerenes (C60) & Propionibacterium acnes, Staphylococcus epidermidis, Candida albicans, & Aoshima et al. 2009 \\
& Malassezia furfur & \\
Fullerene-based particles (nC60) & Pseudomonas mendocina & Lyon et al. 2008b \\
Fullerene (nC60) & Escherichia coli & Lyon et al. 2008c \\
Fullerene water suspensions & Bacillus subtilis & Lyon et al. 2006 \\
C60-water suspension (nano-C60) & Escherichia coli, Bacillus subtilis & Lyon et al. 2005 \\
Buckminsterfullerene (C60) & Pseudomonas putida, Bacillus subtilis & Fang et al. 2007 \\
$\begin{array}{l}\text { Porphyrin-fullerene C60 dyad } \\
\text { (TCP-C60) }\end{array}$ & Staphylococcus aureus, Escherichia coli & Ballatore et al. 2015 \\
Fullerene derivatives bearing & Escherichia coli & Deryabin et al. 2014 \\
amine (AF) & & Mizuno et al. 2011 \\
Cationic-substituted fullerene & Staphylococcus aureus, Escherichia coli, Candida albicans & Nakamura and Mashino 2009 \\
C60-dimalonic acid & Escherichia coli & Zhang et al. 2015 \\
Cationic fullerene (LC16) & Acinetobacter baumannii, methicillin-resistant Staphylococcus & aureus, \\
& Candida albicans & \\
\hline
\end{tabular}


Table 2. Antibiofilm activity of NMs.

\begin{tabular}{|c|c|c|}
\hline Type of NMs & Target organism & Ref. \\
\hline Ag NPs & marine biofilms were grown in situ in a coastal site (Singapore Harbour) & Fabrega et al. 2011 \\
\hline Ag NPs & sixteen different marine biofilm forming bacterial strains & Inbakandan et al. 2013 \\
\hline Ag NPs & Pseudomonas aeruginosa, Staphylococcus epidermidis, Escherichia coli & Kalishwaralal et al. 2010 \\
\hline Ag NPs & Pseudomonas aeruginosa & Martinez-Gutierrez et al. 2013 \\
\hline Ag NPs & Candida albicans, Candida glabrata & Monteiro et al. 2011, 2012 \\
\hline Ag NPs & $\begin{array}{l}\text { a marine microalga Dunaliella tertiolecta and a freshwater green alga } \\
\text { community. }\end{array}$ & Ren et al. 2014 \\
\hline Ag NPs & $\begin{array}{l}\text { Escherichia coli, Enterococcus, Staphylococcus aureus, } \\
\text { coagulase-negative staphylococci, Pseudomonas aeruginosa, Candida } \\
\text { albicans }\end{array}$ & Roe et al. 2008 \\
\hline Ag NPs & Thiotrichales and other wastewater biofilms bacteria & Sheng and Liu 2011 \\
\hline $\begin{array}{l}\text { ELE-Ag NPs synthesized by } \\
\text { using aqueous leaf extract of } \\
\text { Eucalyptus globulus (ELE) }\end{array}$ & Staphylococcus aureus, Pseudomonas aeruginosa & Ali et al 2015 \\
\hline $\begin{array}{l}\text { Gum arabic capped-silver } \\
\text { nanoparticles (GA-Ag NPs) }\end{array}$ & multi-drug resistant (MDR) Pseudomonas aeruginosa & Ansari et al. 2014 \\
\hline $\begin{array}{l}\text { Biogenic Ag NPs synthesized } \\
\text { using tea extract }\end{array}$ & Staphylococcus aureus, Escherichia coli & Goswami et al. 2015 \\
\hline
\end{tabular}




\begin{tabular}{|c|c|c|}
\hline $\begin{array}{l}\text { Ag NPs using a novel plant } \\
\text { extract of } A \text {. cobbe combinated } \\
\text { with conventional antibiotics } \\
\text { (ampicillin and vancomycin) }\end{array}$ & $\begin{array}{l}\text { Pseudomonas aeruginosa, Shigella flexneri, Staphylococcus aureus, } \\
\text { Streptococcus pneumonia }\end{array}$ & Gurunathan et al. 2014 \\
\hline Citrate-capped Ag NPs & Pseudomonas aeruginosa $\mathrm{PAO} 1$ & Habash et al. 2014 \\
\hline Kocuran-capped Ag NPs & Staphylococcus aureus, Escherichia coli & Kumar et al. 2014 \\
\hline Starch-stabilized Ag NPs & Staphylococcus aureus, Pseudomonas aeruginosa PAO1 & Mohanty et al. 2012 \\
\hline Chitosan-stabilized Ag NPs & Pseudomonas aeruginosa, Staphylococcus aureus & Prajna Jena 2012 \\
\hline Colloidal nanostructured silver & athogenic strains & Shahrokh and Emtiazi 2013 \\
\hline $\begin{array}{l}\text { Bacillus licheniformis cell free } \\
\text { extract (BLCFE) coated Ag NPs }\end{array}$ & Vibrio parahaemolyticus Dav1 & Shanthi et al. 2016 \\
\hline $\begin{array}{l}\text { Mycofabricated biosilver } \\
\text { nanoparticles (mfAg NPs) }\end{array}$ & Pseudomonas aeruginosa & Singh et al. $2015 \mathrm{c}$ \\
\hline $\mathrm{Ag}-\mathrm{TiO}_{2}$ nanocomposites & $\begin{array}{l}\text { Bacillus subtilis IC 12488, Staphylococcus aureus IC } 13204, \\
\text { Escherichia coli IC } 13147 \text { and IC13529, Klebsiella pneumoniae } 1204 \\
\text { and IC } 13420\end{array}$ & Lungu et al. 2014 \\
\hline $\mathrm{AgCl}-\mathrm{TiO}_{2} \mathrm{NPs}$ & Chromobacterium violaceum & Naik and Kowshik 2014 \\
\hline $\begin{array}{l}\text { Epoxy/Ag- } \mathrm{TiO}_{2} \\
\text { nanocomposite }\end{array}$ & Staphylococcus aureus ATCC6538, Escherichia coli K-12 & Natarajan 2015 \\
\hline $\mathrm{TiO}_{2} \mathrm{NPs}$ & Candida albicans & Haghighi et al. 2013 \\
\hline $\mathrm{TiO}_{2} \mathrm{NPs}$ & fungal filaments & Shirakawa et al. 2016 \\
\hline $\mathrm{ZnO}$ NPs and $\mathrm{TiO}_{2}$ NPs & Streptococcus mitis ATCC 6249 and Ora-20 & Khan et al. 2016 \\
\hline $\mathrm{ZnO} \mathrm{NPs}$ & Escherichia coli 1313, Staphylococcus aureus 195 & Applerot et al. 2012 \\
\hline $\mathrm{ZnO} \mathrm{NPs}$ & Pseudomonas aeruginosa & Dwivedi et al. 2014 \\
\hline $\mathrm{ZnO} \mathrm{NPs}$ & Pseudomonas aeruginosa & Lee et al. 2014 \\
\hline $\mathrm{ZnO} \mathrm{NPs}$ & Pseudomonas aeruginosa & Garcia-Lara et al. 2015 \\
\hline
\end{tabular}




\begin{tabular}{|c|c|c|}
\hline $\mathrm{ZnO} \mathrm{NPs}$ & Pseudomonas aeruginosa & Hassani Sangani et al. 2015 \\
\hline $\mathrm{ZnO}$ and $\mathrm{CuO} \mathrm{NPs}$ & Streptococcus mutans & Eshed et al. 2012 \\
\hline $\begin{array}{l}\text { Core/shell ( } \mathrm{ZnO} / \text { polyacrylamide) } \\
\text { nanocomposite } \\
(\mathrm{ZnO} / \mathrm{PAM} . \mathrm{NC} 10)\end{array}$ & Bacillus subtilis, Escherichia coli & Morsi et al. 2016 \\
\hline $\begin{array}{l}\text { Magnetite Nanostructure }\left(\mathrm{Fe}_{3} \mathrm{O}_{4}\right) \\
\text { NPs modified with Satureja } \\
\text { hortensis essential oil }\end{array}$ & Candida albicans ATCC 10231 & Anghel et al. 2013 \\
\hline Ferromagnetic $\left(\mathrm{Fe}_{3} \mathrm{O}_{4}\right) \mathrm{NPs}$ & Escherichia coli, Pseudomonas aeruginosa & Gao et al. 2014 \\
\hline Iron-oxide $\left(\mathrm{Fe}_{3} \mathrm{O}_{4}\right) \mathrm{NPs}$ & Staphylococcus aureus, Escherichia coli, Pseudomonas aeruginosa & Thukkaram et al. 2014 \\
\hline Gold nanorods (AuNRs) & $\begin{array}{l}\text { Enterococcus faecalis, Staphylococcus aureus, Streptococcus mutans, } \\
\text { Streptococcus sobrinus, Streptococcus oralis, Streptococcus salivarius, } \\
\text { Escherichia coli }\end{array}$ & Castillo-Martínez et al. 2015 \\
\hline Gold and Iron-Oxide NPs & Staphylococcus aureus, Pseudomonas aeruginosa & (Sathyanarayanan et al. 2013) \\
\hline $\begin{array}{lcl}\text { Gold-based } & \text { zinc } & \text { oxide } \\
\text { nanostructures }(\mathrm{Au} @ \mathrm{ZnO}) & \end{array}$ & Pseudomonas aeruginosa & Gholap et al. 2016 \\
\hline $\begin{array}{l}\text { Plant mediated gold NPs using } \\
\text { Garcinia cambogia }\end{array}$ & Bacillus licheniformis & Nithya and Jayachitra 2016 \\
\hline 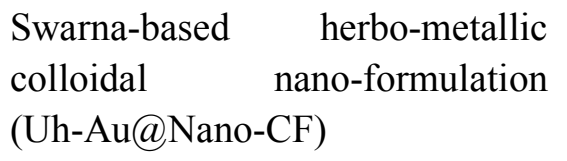 & Streptococcus mutans & Singh et al. $2015 b$ \\
\hline $\mathrm{MgF}_{2} \mathrm{NPs}$ & Streptococcus mutans & Eshed et al. 2013 \\
\hline $\mathrm{MgF}_{2} \mathrm{NPs}$ & Escherichia coli C600, Staphylococcus aureus FRF1169 & Lellouche et al. 2009 \\
\hline Selenium NPs & $\begin{array}{l}\text { Bacillus cereus, Enterococcus faecalis, Staphylococcus aureus, } \\
\text { Escherichia coli O157:H7, Salmonella Typhimurium, Salmonella } \\
\text { Enteritidis }\end{array}$ & Khiralla and El-Deeb 2015 \\
\hline
\end{tabular}




\begin{tabular}{|c|c|c|}
\hline Calcium fluoride $\left(\mathrm{CaF}_{2}\right) \mathrm{NPs}$ & Streptococcus mutans & Kulshrestha et al. 2016 \\
\hline Cuprous oxide $\left(\mathrm{Cu}_{2} \mathrm{O}\right) \mathrm{NPs}$ & Staphylococcus aureus & Singh et al. $2015 \mathrm{a}$ \\
\hline Quanta-CuO & Staphylococcus aureus, Escherichia coli & Tripathy et al. 2016 \\
\hline Natural compound chitosan & $\begin{array}{l}\text { Staphylococcus epidermidis, Staphylococcus aureus, Klebsiella } \\
\text { pneumoniae, Pseudomonas aeruginosa, Candida albicans }\end{array}$ & Carlson et al. 2008 \\
\hline Chitosan NPs & Staphylococcus aureus, Pseudomonas aeruginosa & Darabpour et al. 2016 \\
\hline Chitosan NPs & Streptococcus mutans & de Paz et al. 2011 \\
\hline $\begin{array}{l}\text { Chitosan-stabilized } \\
\text { nanoparticles (CS-AgNPs) }\end{array}$ & Pseudomonas aeruginosa, Salmonella typhi, Staphylococcus aureus & Prajna Jena 2012 \\
\hline Chitosan-based Ag NPs & $\begin{array}{l}\text { Escherichia coli ATCC51813, Staphylococcus aureus ATCC27661, } \\
\text { Bacillus subtilis ATCC6051 }\end{array}$ & Wei et al. 2009 \\
\hline $\begin{array}{l}\text { Chitosan based zinc oxide } \\
\text { nanoparticles ( } \mathrm{ZnO}-\mathrm{CTS} \mathrm{NPs})\end{array}$ & Micrococcus luteus, Staphylococcus aureus & Dhillon et al. 2014 \\
\hline $\begin{array}{l}\beta \quad \text {-N-acetyl-glucosaminidase } \\
\text { immobilizated on carboxymethyl } \\
\text { chitosan NPs }\end{array}$ & $\begin{array}{l}\text { Staphylococcus aureus, Staphylococcus epidermidis, Actinobacillus } \\
\text { actinomycetemcomitans }\end{array}$ & Tan et al. 2015 \\
\hline $\begin{array}{l}\text { Ferulic acid encapsulated } \\
\text { chitosan NPs }\end{array}$ & Candida albicans & Panwar et al. 2016 \\
\hline $\begin{array}{l}\text { Bioactive polymeric chitosan NPs } \\
\text { functionalized with rose-bengal }\end{array}$ & Enterococcus faecalis & Shrestha et al. 2014 \\
\hline Chitosan- $\mathrm{ZnO}$ composite & Vibrio parahaemolyticus, Bacillus lechiniformis & Vaseeharan et al. 2015 \\
\hline Nisin-coated MWCNTs sheet & Bacillus anthracis & Dong et al. 2014 \\
\hline SWCNTs & Bacillus anthracis & Dong and Yang 2014 \\
\hline MWCNTs-nisin composite & Staphylococcus aureus & Qi et al. 2011 \\
\hline
\end{tabular}




\begin{tabular}{lll}
\hline MWCNTs-cefalexin composite & $\begin{array}{l}\text { Escherichia coli, Pseudomonas aeruginosa, Staphylococcus aureus, } \\
\text { Bacillus subtilis }\end{array}$ & Qi et al. 2012 \\
SWCNTs & Escherichia coli & Tiraferri et al. 2011 \\
SWCNTs & Escherichia coli K12 & Rodrigues and Elimelech 2010 \\
Fullerene (C60) & soil bacterial community composition & Tong et al. 2016 \\
$\begin{array}{l}\text { Porphyrin-fullerene C60 dyad } \\
\text { (TCP-C60) }\end{array}$ & Staphylococcus aureus, Escherichia coli & Ballatore et al. 2015 \\
Spice oil nanoemulsions & Chromobacterium violaceum CV026 & Venkadesaperumal et al. 2016 \\
\hline
\end{tabular}


Table 3. Mechanisms and applications of antimicrobial NMs.

\begin{tabular}{|c|c|c|c|c|}
\hline $\begin{array}{l}\text { Type of } \\
\text { NMs }\end{array}$ & $\begin{array}{l}\text { Proposed mechanisms of } \\
\text { antimicrobial action }\end{array}$ & $\begin{array}{l}\text { Factors that influence } \\
\text { antimicrobial activity }\end{array}$ & Applications & Ref. \\
\hline $\mathrm{Ag}$ & $\begin{array}{l}\text { Release of } \mathrm{Ag}^{+} \text {ions; } \\
\text { disruption of cell membrane } \\
\text { and electron transport; DNA } \\
\text { damage }\end{array}$ & $\begin{array}{l}\text { Particle size and shape; surface } \\
\text { area; type of coating; } \mathrm{Ag}^{+} \\
\text {release; type of microorganism. }\end{array}$ & $\begin{array}{l}\text { Dressing for surgical wound and } \\
\text { diabetic foot; antibacterial agent; } \\
\text { portable water filters; coatings for } \\
\text { medical devices, refrigerators, and } \\
\text { food containers; }\end{array}$ & $\begin{array}{l}\text { (Pal et al. 2007; Li et al. } \\
\text { 2008b; Blecher et al. 2011; } \\
\text { Huh and Kwon 2011; } \\
\text { Knetsch and Koole 2011) }\end{array}$ \\
\hline $\mathrm{TiO}_{2}$ & $\begin{array}{l}\text { Production of ROS; cell } \\
\text { membrane and cell wall } \\
\text { damage. }\end{array}$ & $\begin{array}{l}\text { Particle size and shape; } \\
\text { concentration of } \mathrm{TiO}_{2} \text {; type of } \\
\text { microorganism; intensity and } \\
\text { wavelength of light; degree of } \\
\text { hydroxylation; pH; } \\
\text { temperature; availability of } \\
\text { oxygen; retention time. }\end{array}$ & $\begin{array}{l}\text { Air purifiers; water treatment } \\
\text { systems for organic contaminant } \\
\text { degradation; antibacterial agent; } \\
\text { food sterilizing agent }\end{array}$ & $\begin{array}{l}\text { (Maness et al. 1999; } \\
\text { Oppezzo and Pizarro 2001; } \\
\text { Kühn et al. 2003; Choi et al. } \\
\text { 2007b; Reddy et al. 2007b) }\end{array}$ \\
\hline $\mathrm{ZnO}$ & $\begin{array}{l}\text { Formation of ROS; } \\
\text { Interaction of NPs with }\end{array}$ & $\begin{array}{l}\text { Particle size and shape; particle } \\
\text { concentration; solvent and } \mathrm{pH} \text {; }\end{array}$ & $\begin{array}{l}\text { Antibacterial creams; lotions and } \\
\text { ointment; deodorant; self-cleaning }\end{array}$ & $\begin{array}{l}\text { (Sawai et al. 1998; Zhang et } \\
\text { al. 2008; Gordon et al. 2011; }\end{array}$ \\
\hline
\end{tabular}




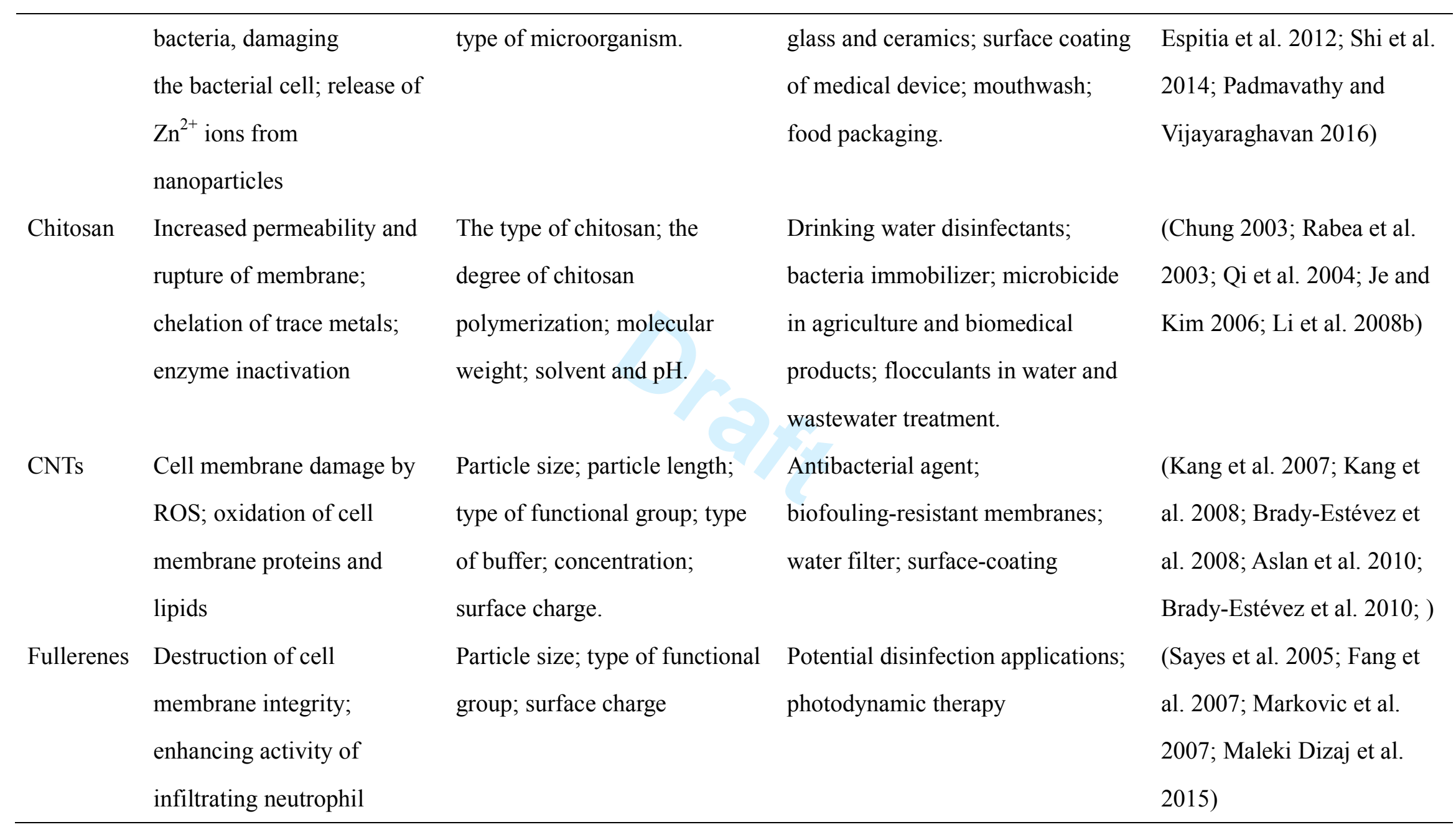


Table 4. Similarities and differences among $\mathrm{Ag}, \mathrm{TiO}_{2}$ and $\mathrm{ZnO}$ NPs.

\begin{tabular}{|c|c|c|c|c|}
\hline \multirow{2}{*}{$\begin{array}{l}\text { Factors } \\
\text { Similarities } \\
\end{array}$} & & $\mathrm{Ag}$ & $\mathrm{TiO}_{2}$ & $\mathrm{ZnO}$ \\
\hline & Synthesis & \multicolumn{3}{|c|}{ Several synthesis routes allow for better control of shape and size. } \\
\hline \multirow{3}{*}{$\underline{\text { Similarities }}$} & $\begin{array}{l}\text { Antimicrobial } \\
\text { activity }\end{array}$ & \multicolumn{3}{|c|}{ Exhibit antibacterial activity against gram-positive and gram-negative bacteria as well as fungi. } \\
\hline & $\begin{array}{l}\text { Potential } \\
\text { toxicity }\end{array}$ & \multicolumn{3}{|c|}{ Due to their small sizes and variable properties, they may be hazardous to the human health and environment. } \\
\hline & Cost & \multicolumn{3}{|c|}{ Depending on the synthesis method, they can each be prepared in a cost-effective manner. } \\
\hline \multirow{3}{*}{ Differences } & Regulation & $\begin{array}{l}\text { EU safety regulations limit the } \\
\text { presence of silver ions in food } \\
\text { matrices to } 0.05 \mathrm{mg} \mathrm{Ag} / \mathrm{kg} \text {. }\end{array}$ & $\begin{array}{l}\text { Pure } \mathrm{Ti} \text { and } \mathrm{TiO}_{2} \text { are extensively used } \\
\text { for dental and orthopedic implants } \\
\text { owing to their high mechanical } \\
\text { properties and biocompatibility. } \\
\mathrm{TiO}_{2} \text { dust, when inhaled, has recently } \\
\text { been classified by the International } \\
\text { Agency for Research on Cancer (IARC) } \\
\text { as an IARC Group 2B carcinogen } \\
\text { possibly carcinogenic to humans. }\end{array}$ & $\begin{array}{l}\mathrm{ZnO} \text { has been used in } \\
\text { foodstuffs due to its ability to } \\
\text { decompose into } \mathrm{Zn} \text { ions in the } \\
\text { human body. } \\
\text { It is currently listed by the } \\
\text { FDA as a "generally } \\
\text { recognized as safe (GRAS)" } \\
\text { material. }\end{array}$ \\
\hline & $\begin{array}{l}\text { Antimicrobial } \\
\text { mechanism }\end{array}$ & $\begin{array}{l}\text { It is largely attributed to the release } \\
\text { of } \mathrm{Ag}^{+} \text {. }\end{array}$ & $\begin{array}{l}\text { The photocatalytic antibacterial activity } \\
\text { is attributed to ROS under UV light }\end{array}$ & $\begin{array}{l}\text { Production of ROS and release } \\
\text { of } \mathrm{Zn}^{2+} \text { ions. }\end{array}$ \\
\hline & Toxicity & It has some risks when used as a & Bulk $\mathrm{TiO}_{2}$ particles $(>100 \mathrm{~nm})$ are & $\mathrm{ZnO}$ has litter toxicity in bulk \\
\hline
\end{tabular}


evaluation

drug disinfectant such as causing argyrosis and argyria, especially when large amounts of silver ions are used on an open wound.

However, silver is nontoxic to humans in minute concentrations. known to be harmless to humans and animals. High dosage of inhalation nano- $\mathrm{TiO}_{2}$ can act as a pulmonary inflammation agent and be harmful for body tissues. size. $\mathrm{ZnO}$ NPs have been shown to reduce the viability of human $T$ cells at an elevated concentration. Its toxicity effects were dose dependent rather than size dependent. 